Article

\title{
Performance Optimization of a Diesel Engine with a Two-Stage Turbocharging System and Dual-Loop EGR Using Multi-Objective Pareto Optimization Based on Diesel Cycle Simulation
}

\author{
Heecheong Yoo ${ }^{1}$, Bum Youl Park ${ }^{2}$, Honghyun $\mathrm{Cho}^{3}$ and Jungsoo Park ${ }^{3, *}$ \\ 1 Department of Mechanical Engineering, Hyundai Motor Company, Gyeonggi-do 18280, Korea; \\ hcyoo@hyundai.com \\ 2 Department of Mechanical Design Engineering, Hanyang University, 55, Hanyang University, \\ Gyeonggi-do 15588, Korea; pby9074@koreard.co.kr \\ 3 Department of Mechanical Engineering, Chosun University, Gwangju 61452, Korea; hhcho@chosun.ac.kr \\ * Correspondence: j.park@chosun.ac.kr
}

Received: 16 October 2019; Accepted: 1 November 2019; Published: 6 November 2019

check for updates

\begin{abstract}
The effects of an electric supercharger (eS) and a dual-loop exhaust gas recirculation (EGR) system on a passenger car's diesel engine's emissions and fuel efficiency under various worldwide harmonized light-duty vehicles test procedure (WLTP) reference operation points were investigated using a one-dimensional engine cycle simulation, called GT-Power. After heavy EGR application, the in-cylinder pressure and temperature declined due to a dilution effect. As eS power and rpm increased, the brake-specific fuel consumption (BSFC) decreased because the effects of the air flow rate increased. However, it was unavoidable that nitrogen oxide $\left(\mathrm{NO}_{\mathrm{x}}\right)$ emissions also increased due to the higher in-cylinder pressure and temperature. To induce more EGR to the intake system, a dual-loop EGR system was applied with eS at different low-pressure EGR (LP-EGR) fractions (0, $0.25,0.5,0.75$, and 1.0). Under these conditions, a design of experiment (DoE) procedure was carried out and response surface plots of the BSFC and brake-specific $\mathrm{NO}_{\mathrm{x}}\left(\mathrm{BSNO}_{\mathrm{x}}\right)$ were prepared. A multi-objective Pareto optimization method was used to improve the trade-off in results between the BSFC and $\mathrm{BSNO}_{\mathrm{x}}$. Through optimization, optimal Pareto fronts were obtained, which suggested design parameters for $\mathrm{eS}$ power and rpm to control the engine under various LP fraction conditions.
\end{abstract}

Keywords: 1D engine cycle simulation; dual-loop EGR; electric supercharger; design of experiment; multi-objective Pareto optimization

\section{Introduction}

As regulations for passenger cars are being strengthened nowadays, conventional passenger cars with gasoline and diesel engines should be improved to provide better fuel efficiency and reduced emissions. Diesel engines have the advantage of better fuel efficiency to meet such $\mathrm{CO}_{2}$ emission regulations; however, given their compression ignition $(\mathrm{CI})$ combustion characteristics, emissions of dangerous materials, such as nitrogen oxide $\left(\mathrm{NO}_{\mathrm{x}}\right)$ and particulate matter $(\mathrm{PM})$, are inevitable. Thus, regulations for passenger cars are being strengthened to meet 'worldwide harmonized light-duty vehicles test procedures' (WLTP) or 'real driving emission cycle' (RDE), which can describe real driving conditions during the test mode [1].

However, as these regulations are becoming increasingly harsh, further advanced technologies, such as heavy exhaust gas recirculation (EGR), dual-loop EGR, and two-stage turbocharging with 
an electric supercharger (eS), need to be investigated to satisfy them. One issue here is that as boost pressure increases, fuel efficiency improves, but increased emissions are also inevitible [1].

To reduce the major emissions of $\mathrm{CI}$ engines, such as $\mathrm{NO}_{\mathrm{x}}$ and $\mathrm{PM}$, many after-treatment systems have been applied to passenger car diesel engines. Such after-treatment systems are expensive, so reducing emissions by other mechanisms, such as with low-temperature combustion (LTC), should be investigated. A well-controlled LTC engine can improve fuel efficiency and reduce $\mathrm{NO}_{\mathrm{x}}$ and PM emissions without an after-treatment system.

Commensurate with the increased need for LTC, the importance of EGR is emerging. Heavy EGR should be applied to reduce the combustion temperature. However, as the EGR induction rate increases, several problems, such as EGR induction and boost pressure shortages-due to reduced mass flow rate to the turbocharger-have emerged [2-9]. To address these problems, dual-loop EGR systems and two-stage turbochargers need to be investigated.

Conventional EGR systems use only high-pressure EGR (HP-EGR) or low-pressure EGR (LP-EGR) systems. Table 1 shows the advantages and shortcomings of each system. HP-EGR responds rapidly to lower speed or low loads, but EGR induction is limited when the turbine inlet pressure is sufficiently higher than the intake manifold pressure. When these two systems are applied together to an engine EGR system, it is called a dual-loop EGR system. Dual-loop EGR systems have the advantage of being able to optimize the EGR rate under many driving conditons [10-12]. Experimental studies with dual-loop EGR systems were reported by Cho et al. [13]. They studied a high-efficiency clean-combustion (HECC) engine and compared the performance of HP and LP dual-loop EGR systems under five operating conditions. Adachi et al. [6] and Kobayashi et al. [7] investigated the combination of both high boost pressure from a turbocharger and a high rate of EGR with respect to reducing the brake-specific $\mathrm{NO}_{x}\left(\mathrm{BSNO}_{\mathrm{x}}\right)$ and PM. Park et al. [14] studied the effects of an EGR split index (ESI) of a dual-loop EGR system numerically. Using an LP-rich dual-loop EGR, a high EGR rate could be applied for low, medium, and high speeds, increasing the applicable load ranges versus the base conditions.

Table 1. Advantages and shortcomings of two types of EGR.

\begin{tabular}{|c|c|c|}
\hline Type & Advantages & Shortcomings \\
\hline HP-EGR & $\begin{array}{l}\text { - } \quad \text { Lower } \mathrm{HC} \text { and } \mathrm{CO} \text { emissions } \\
\text { - } \quad \text { Fast response }\end{array}$ & $\begin{array}{ll}\text { - } & \text { Cooler fouling } \\
\text { - } & \text { Unstable cylinder distribution } \\
\text { - } & \text { Not capable of heavy EGR supply }\end{array}$ \\
\hline LP-EGR & $\begin{array}{ll}\text { - } & \text { Lower temperature EGR } \\
\text { - } & \text { Clean EGR (no fouling) } \\
\text { - } & \text { Stable cylinder distribution } \\
& \text { Beavy EGR supply capability }\end{array}$ & $\begin{array}{l}\text { - } \quad \text { Compressor corrosion due to condensation water } \\
\text { - } \quad \text { Slow response } \\
\text { HCO increases }\end{array}$ \\
\hline
\end{tabular}

A conventional turbocharger system with a single-stage turbocharger is a widely used method for improving fuel efficiency. However, it is hard to avoid turbo lag, due to turbine inertia, and to improve the boost pressure in the case of heavy EGR operation, due to the decrease in the turbine inlet flow rate. To overcome these weaknesses, a two-stage turbocharger system with eS should be investigated. By applying eS, it is easy to improve transient responses and to improve boost pressure under heavy EGR conditions.

Mattarelli [15] investigated various two-stage turbocharging systems and compared them in terms of the steady state at the New European Driving Cycle (NEDC) test reference operation points. Tang et al. [16,17] investigated the effects of various turbocharging approaches on gasoline engine transient conditions. They found that applying an electric turbo charging system improved transient responses and fuel efficiency. Salehi et al. [18] investigated the effects of high and low pressure eSs on a heavy duty diesel engine, for both steady state and transient operations, and found that LP eS 
was more efficient with respect to transient responses, although the high engine speed response was improved with an HP eS.

The aim of this paper was to optimize the thermal performance and emissions of diesel engine considering dual-loop EGR and eletric supercharger under steady-state rpm-load conditions, representing the frequently selected operating conditions from the WLTP for the test of real engines. To achieve the research goal, multi objective Pareto optimization was applied based on thermodynamic cycle simulation results, including the detailed multi-zone combustion model for a compression ignition direct injection (CIDI) engine, the heat transfer model for each component, such as EGR and EGR cooler, and the thermal performance of the electric supercharger. Starting from the validation of the base engine model, which describes engine operation based on the OEM(Original Equipment Manufacturer)'s test results for WLTP, performance, in terms of fuel efficiency and emission characteristics, was investigated through brake-specific fuel consumption (BSFC) and BSNO ${ }_{x}$ under various WLTP reference load conditions. Heavy EGR was applied to reduce $\mathrm{NO}_{\mathrm{x}}$ emissions. To improve fuel efficiency and $\mathrm{NO}_{x}$ emissions simultaneously, both the dual-loop EGR system and eS effects on the engine were investigated with a design of experiment (DoE) and multi-objective Pareto optimization method. The main goal of this study was to lower BSNO $x$ and BSFC, via a trade-off curve by means of LTC (Low Temperture Combustion), and to suggest design parameters for various engine operating conditons using a multi-objective Pareto optimization method.

\section{Methodology}

A one-dimensional (1D) engine cycle simulation tool, called GT-Power (Gamma Technologies) [19], was used to investigate engine performance outcomes numerically, in terms of the BSFC, $\mathrm{BSNO}_{\mathrm{x}}$, brake mean effective pressure (BMEP), and air fuel (A/F) ratio. The base engine model was validated by comparison with expermental data. The base passenger car diesel engine specifications are shown in Table 2. The reference operating and selected WLTP points are shown in Figure 1. The operating conditions of the base engine were 4 bar of BMEP at $1500 \mathrm{rpm}, 6$ and 8 bar of BMEP at $1750 \mathrm{rpm}, 10 \mathrm{bar}$ of BMEP at $2000 \mathrm{rpm}$, and 12 bar of BMEP at $2250 \mathrm{rpm}$. To achieve more validated points (marked with green triangles in Figure 1), additional rpm-load conditions were peaked to predict and to optimize the target engine. As a result, there were five validation points (red triangles in Figure 1) to get modeling accuracy and five prediction points (green triangles in Figure 1) that were not covered by the real engine test. Detailed operating conditions are shown in Table 3. The overall research plan is shown in Figure 2.

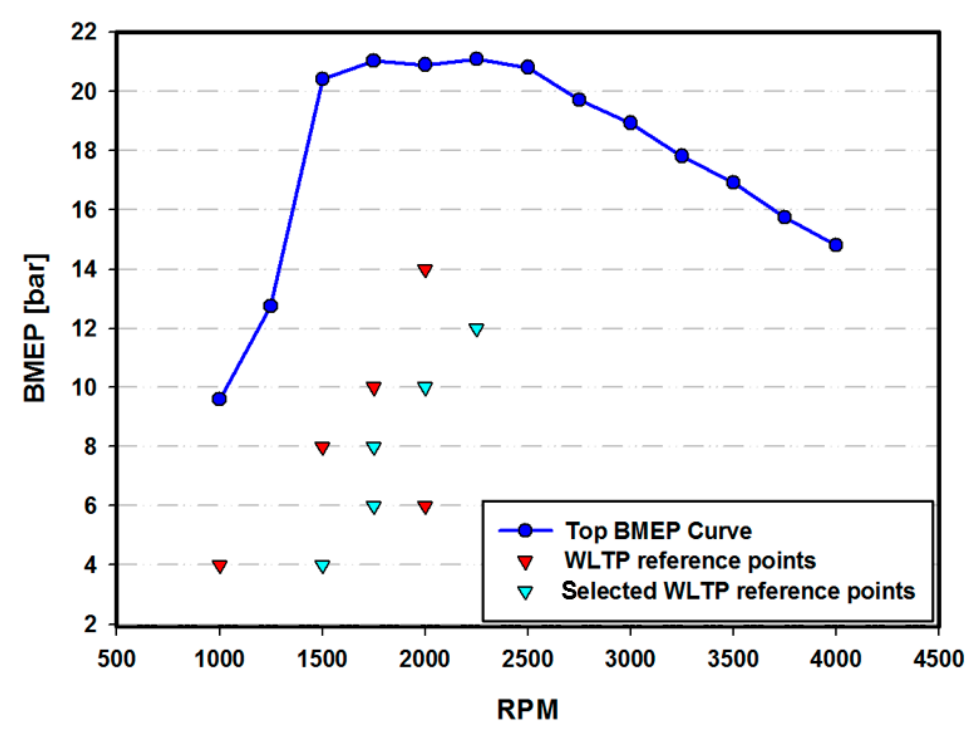

Figure 1. Worldwide harmonized light-duty vehicles test procedure (WLTP) reference points and selected reference points. 
Table 2. Engine specifications.

\begin{tabular}{cc}
\hline Item & Specification \\
\hline Engine type & In-line four cylinders \\
Displacement $(\mathrm{cc})$ & 1396 \\
Bore $(\mathrm{mm})$ & 75 \\
Stroke $(\mathrm{mm})$ & 79 \\
Connecting rod (mm) & 140 \\
Compression ratio & $17: 1$ \\
Maximum power & $67 \mathrm{~kW} @ 4000 \mathrm{rpm}$ \\
Maximum torque & $22.4 \mathrm{kgm} @ 1500 \sim 2750 \mathrm{rpm}$ \\
Injection type & Common rail direct injection \\
EGR system & High pressure EGR \\
Firing order & $1-3-4-2$ \\
\hline
\end{tabular}

Table 3. Detailed operating conditions of the selected WLTP reference points.

\begin{tabular}{cccccc}
\hline Case No. & $\mathbf{1}$ & $\mathbf{2}$ & $\mathbf{3}$ & $\mathbf{4}$ & $\mathbf{5}$ \\
\hline Engine speed (rpm) & 1500 & 1750 & 1750 & 2000 & 2250 \\
BMEP (bar) & 4 & 6 & 8 & 10 & 12 \\
Boost pressure (bar) & 1.09 & 1.22 & 1.37 & 1.67 & 1.93 \\
Rail pressure (bar) & 538 & 795 & 889 & 1084 & 1243 \\
Injected mass (mg/stroke) & 9.43 & 13.93 & 17.89 & 21.97 & 25.59 \\
Pilot1 injection timing (CA BTDC) & 23.28 & 25.9 & 25.34 & 25.08 & 27.28 \\
Pilot2 injection timing (CA BTDC) & 12.41 & 13.9 & 13.4 & 15.22 & 16.27 \\
Main injection timing (CA BTDC) & -5.66 & -5.4 & -5.07 & -4.6 & -3.89 \\
EGR rate (\%) & 31.4 & 26.4 & 17.4 & 16.3 & 6.1 \\
\hline
\end{tabular}

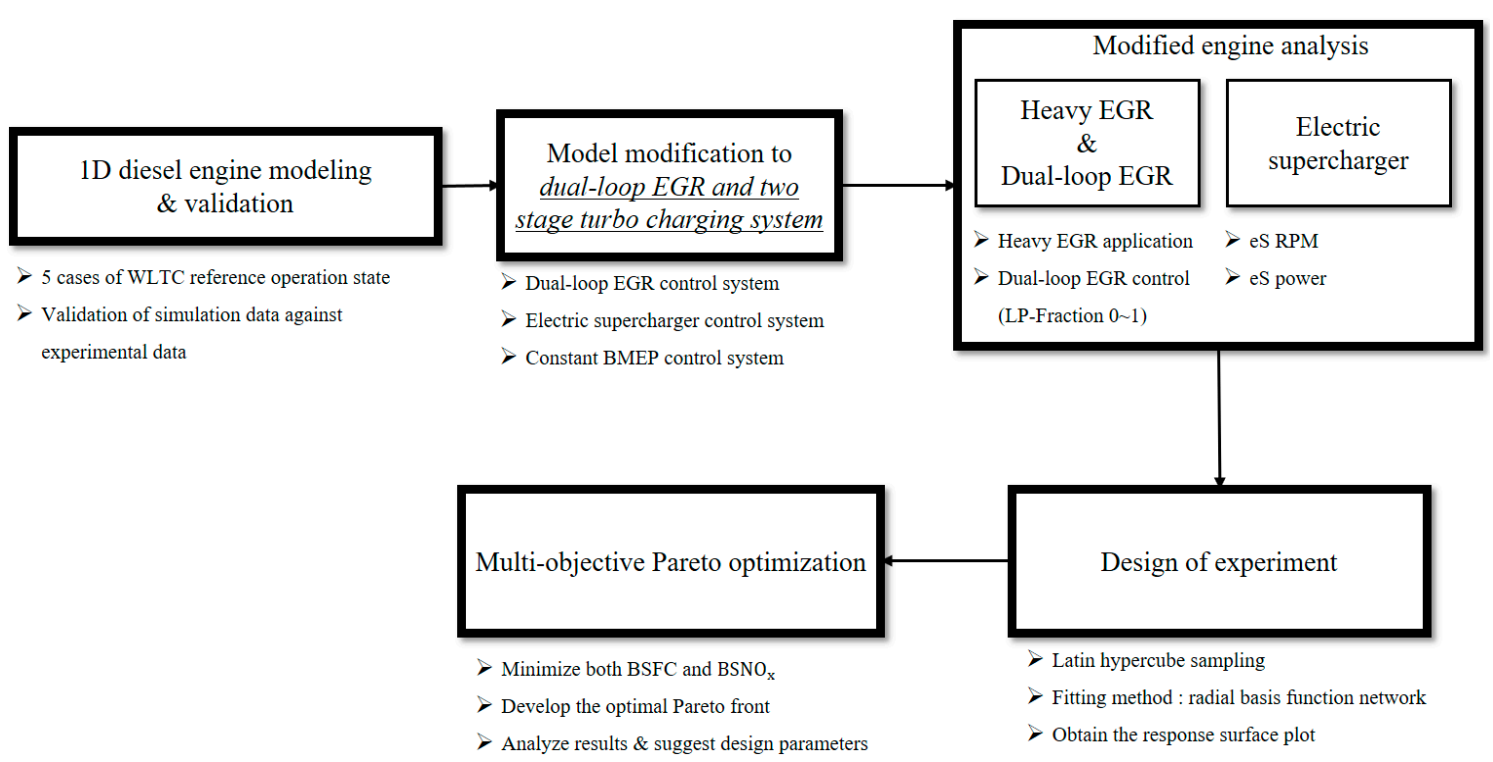

Figure 2. Overview of the research plan.

\subsection{D Engine Modeling and System Modifications}

First, an engine model was prepared based on hardware specifications (bore, stroke, connecting-rod length, top dead center (TDC) clearance height, and compression ratio), intake/exhaust valve profiles, a performance map-based waste gate-type single-stage turbocharger system and intercooler, diesel fuel injection profiles, and EGR systems with an EGR valve and EGR cooler. To meet the required properties, proportional integral derivative (PID) controllers for the EGR fraction and target boost pressure controllers were attached to the engine. 
A $\mathrm{NO}_{x}$ predictive combustion model, the direct-injection diesel multi-pulse (DI-pulse), was used to calibrate the diesel combustion. In the DI-pulse model, injected fuel is tracked during its injection, evaporation, mixing with surrounding gases, and burning through three thermodynamic zones, which have their own temperatures and compositions. The three zones consist of the main unburned zone, the spray unburned zone, and the spray burned zone. The main unburned zone contains all of the cylinder substances at the intake valve closing (IVC). The spray unburned zone contains injected fuel and entrained gases. The spray burned zone contains the combustion products. In the DI-pulse model, fuel is injected in pulses, which are tracked separately. Injected fuel is added to the spray unburned zone and, immediately, the injected fuel penetrates and slows down, mixing with the surrounding unburned and burned gases. The mixing process occurs through entrainment and the mixed gas is referred to as the entrained gas. The entrainment rate is determined by applying the conservation of momentum to an empirical spray penetration law. The fuel is heated by the surrounding gases, causing evaporation, and the entrained gas is mixed in a turbulence-driven process. The mixture for each pulse ignites with its own ignition delay, modeled by the Arrhenius expression. When pulse ignition starts, a premixed combustion occurs first, but this is assumed to be limited kinetically. After ignition, the remaining unmixed fuel and entrained gas in each pulse start mixing and burning in a diffusion-limited phase. Through this combustion process, $\mathrm{NO}_{\mathrm{x}}$ formation is calculated using the extended Zeldovich mechanism [19]. A diagram of the calibrated in-cylinder pressure with fuel injection using the DI-pulse model is shown in Figure 3.

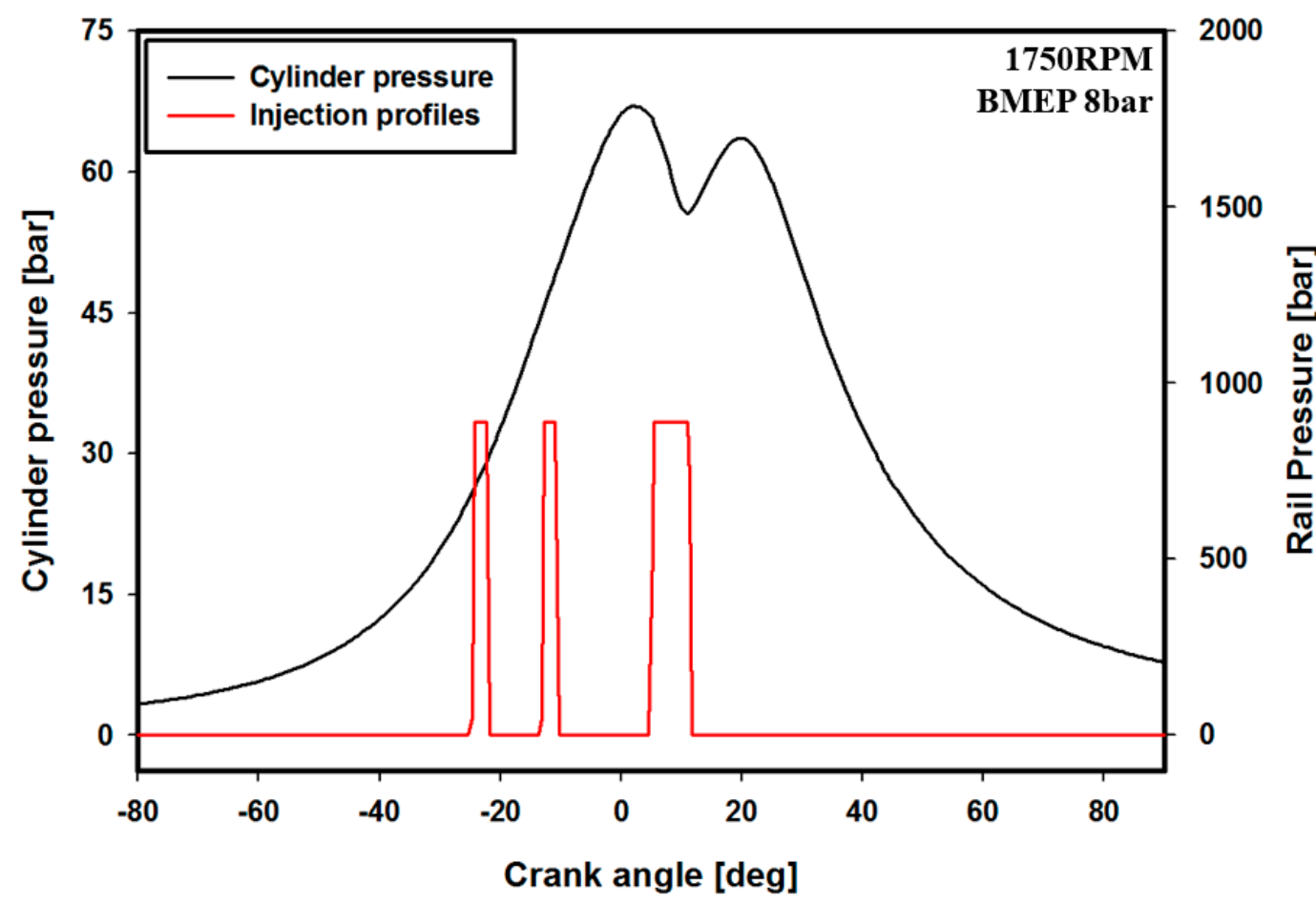

Figure 3. Calibrated in-cylinder pressure diagram with fuel injection using the direct-injection diesel multi-pulse (DI-pulse) combustion model.

After the validation against experimental data, several systems were made and attached to the base engine model. The LP-EGR PID controller was attached to the model and made into a dual-loop EGR control system. The main control factor, i.e., the LP-fraction, was calculated with Equation (1):

$$
\text { LP-fraction }=\text { Total EGR }- \text { HP Fraction/(1 - HP Fraction). }
$$

Then, the turbocharger compressor and an eS control system were attached, controlled by power and rpm. The system control scheme is shown in Figure 4. To maintain constant BMEP under each 
condition (which differ in EGR rate, LP-fraction, and eS characteristics), a constant BMEP PID controller was attached. After sensing the average BMEP of the engine, to keep the BMEP constant, more fuel was injected into the cylinder to increase the BMEP, or the fuel flow rate was lowered to decrease it. The overall control scheme of the constant BMEP controller is shown in Figure 5.

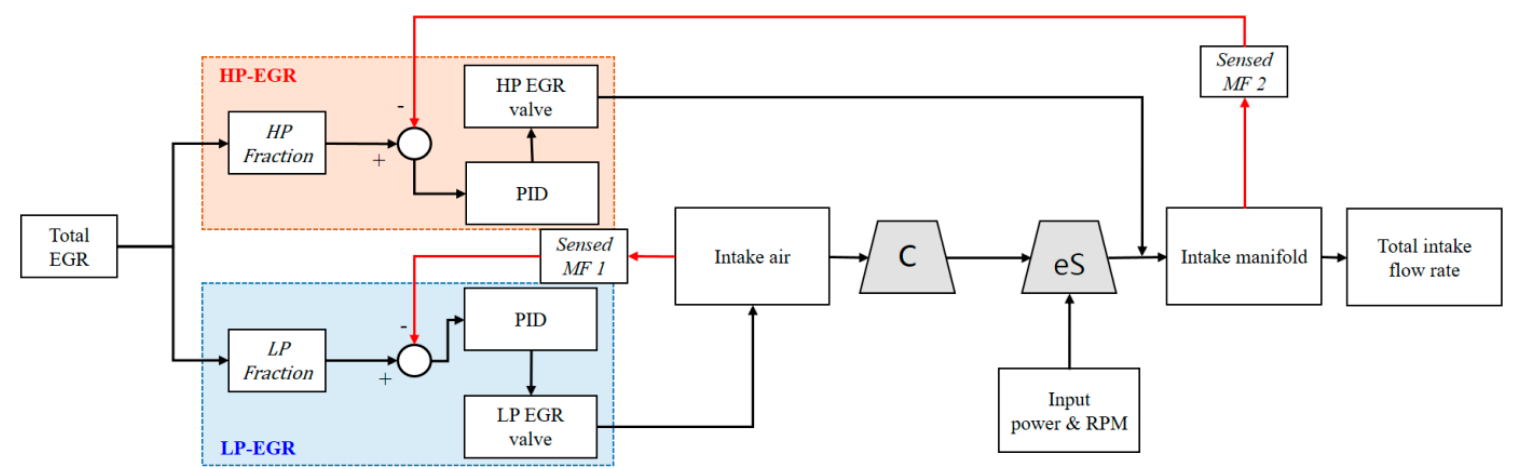

Figure 4. Overall control scheme of the dual-loop exhaust gas recirculation (EGR) and electric supercharger $(\mathrm{eS})$ systems.

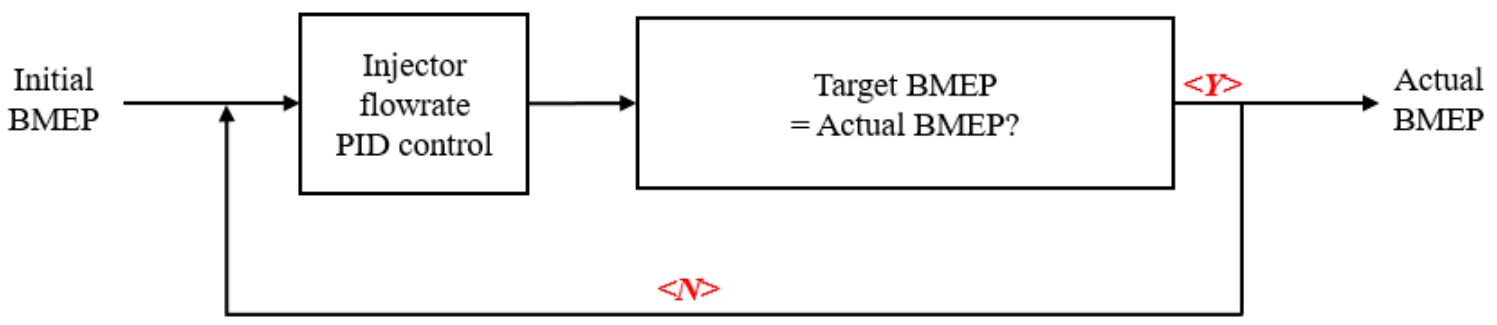

Figure 5. Overall control scheme of the constant brake mean effective pressure (BMEP) controller.

\subsection{DoE with Latin Hypercube Sampling (LHS) and Multi-Objective Pareto Optimization}

There are several engine design parameters that are related to each other. To overcome the cost and hardware difficulties associated with experimental testing, DoE and numerical analyses should be sufficiently powerful to model optimal engine operation conditions despite the use of multiple, complex parameters. Usually, a sampling method is used, such as a full-factorial approach or LHS. After the sampling operation, response surface plots are created using various fitting methods, such as the radial basis function network (RBFN), a least-squares method (LSM), or an artificial neural network (ANN). In this investigation, 400 random cases were made using LHS and, after the simulation, RBFN was used to generate the response surface plot, which is a feed-forward neural network consisting of artificial neurons and a dynamically varying structure, to achieve precise predictions $[20,21]$. In Table 4, several of the sampling ranges used for the DoE are shown.

Table 4. Sampling ranges for Latin hypercube sampling of design of experiment.

\begin{tabular}{cccccc}
\hline Case No. & $\mathbf{1}$ & $\mathbf{2}$ & $\mathbf{3}$ & $\mathbf{4}$ & $\mathbf{5}$ \\
\hline Engine speed (rpm) & 1500 & 1750 & 1750 & 2000 & 2250 \\
BMEP (bar) & 4 & 6 & 8 & 10 & 12 \\
LP-fraction (4, 5cases) & $0-0.75$ & $0-1$ & $0-1$ & $0-1$ & $0-1$ \\
eS rpm & $40,000-90,000$ & $40,000-90,000$ & $40,000-120,000$ & $40,000-120,000$ & $40,000-160,000$ \\
eS power (kW) & $0.1-1.5$ & $0.1-1.5$ & $0.1-1.5$ & $0.1-1.5$ & $0.1-1.5$ \\
Number of sampling points & & \multicolumn{7}{c}{400 points for each case } \\
\hline
\end{tabular}

In this investigation, for $\mathrm{eS}$, as the power and rpm increased, the fuel efficiency of the engine was improved, but increasing $\mathrm{NO}_{\mathrm{x}}$ emissions were inevitable due to increased thermal efficiency. To minimize $\mathrm{NO}_{\mathrm{x}}$ emissions and fuel consumption simultaneously, a multi-objective Pareto optimization 
method was used. By applying the optimization, both BSFC and $\mathrm{BSNO}_{\mathrm{x}}$ will be improved, by optimizing multiple input parameters that improve or worsen engine fuel efficiency and emission characteristics simultaneously.

Multi-objective Pareto optimization is a method to determine Pareto-optimal points from a set of possible solutions satisfying multiple evalutation criteria (i.e., multiple objective functions) that conflict with each other. The optimization process with $n$ variables and $m$ objectives can be defined as in Equation (2) [14,20,22-26]. Detailed explations of RBFN, LHS, and Pareto optimization methods can be found in Park etl al.'s previous paper [20]

$$
\min f(x) \text { subject to } x \in X=\left\{x x \in R_{n}, g(x) \leq 0\right\},
$$

with three vectors, defined as $\mathrm{x}=\left[x_{1}, \cdots, x_{n}\right]^{T}$ of an $n$-dimentional decision variable vector, $\mathrm{f}(\mathrm{x})=\left[f_{1}(x), \cdots, f_{m}(x)\right]^{T}$ of an $m$-dimensional objective funtion vector, and $\mathrm{g}(\mathrm{x})=\left[g_{1}(x), \cdots, g_{l}(x)\right]^{T}$ of a 1D constraint condition vector. When there are no solutions satisfying $x \in X$ :

$$
f_{i}(x) \leq f_{i}\left(x^{*}\right), \quad{ }_{i}=\{1, \cdots, m\} \text { and } f_{i}(x)<f_{i}\left(x^{*}\right),{ }^{\exists} i=\{1, \cdots, m\},
$$

$x^{*} \in X$ is referred to as a Pareto-optimal solution. The overall process flow of the multi-objective Pareto optimization is shown in Figure 6. In this investigation, a simulation range selection was made first; LHS was performed for each case, the RBFN fitting method was applied, and finally the multi-objective Pareto optimization was performed and Pareto fronts were obtained through the objective function spaces of $f_{1}$ and $f_{2}$, for $\mathrm{BSNO}_{\mathrm{x}}$ and BSFC, respectively.

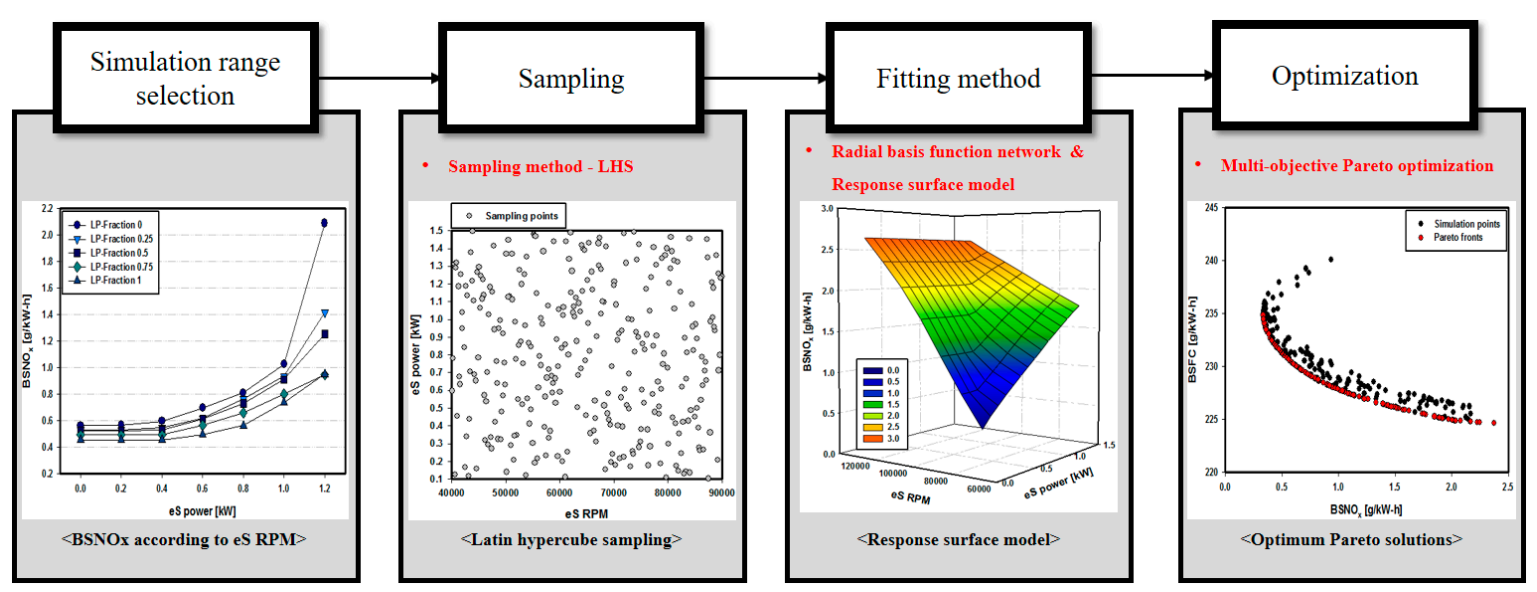

Figure 6. Overall process flow of the multi-objective Pareto optimization.

\section{Results and Discussion}

\subsection{Validation and Heavy EGR Application}

Before applying the control systems (eS, dual-loop EGR, and constant BMEP controller), in each case several numerical results were validated against experimental data using the operational characteristics listed in Table 3. Through this validation, we confirmed that the engine model was accurate for investigations. In Figure 7, comparisons between experimental and numerical results are illustrated in terms of base engine results and major control factors. Boost pressure, EGR rate, maximum in-cylinder pressure (Pmax), BSFC, $\mathrm{BMEP}$, and $\mathrm{BSNO}_{\mathrm{x}}$ were compared against experimental results. The maximum error was $<3 \%$, confirming that the results were reliable. 


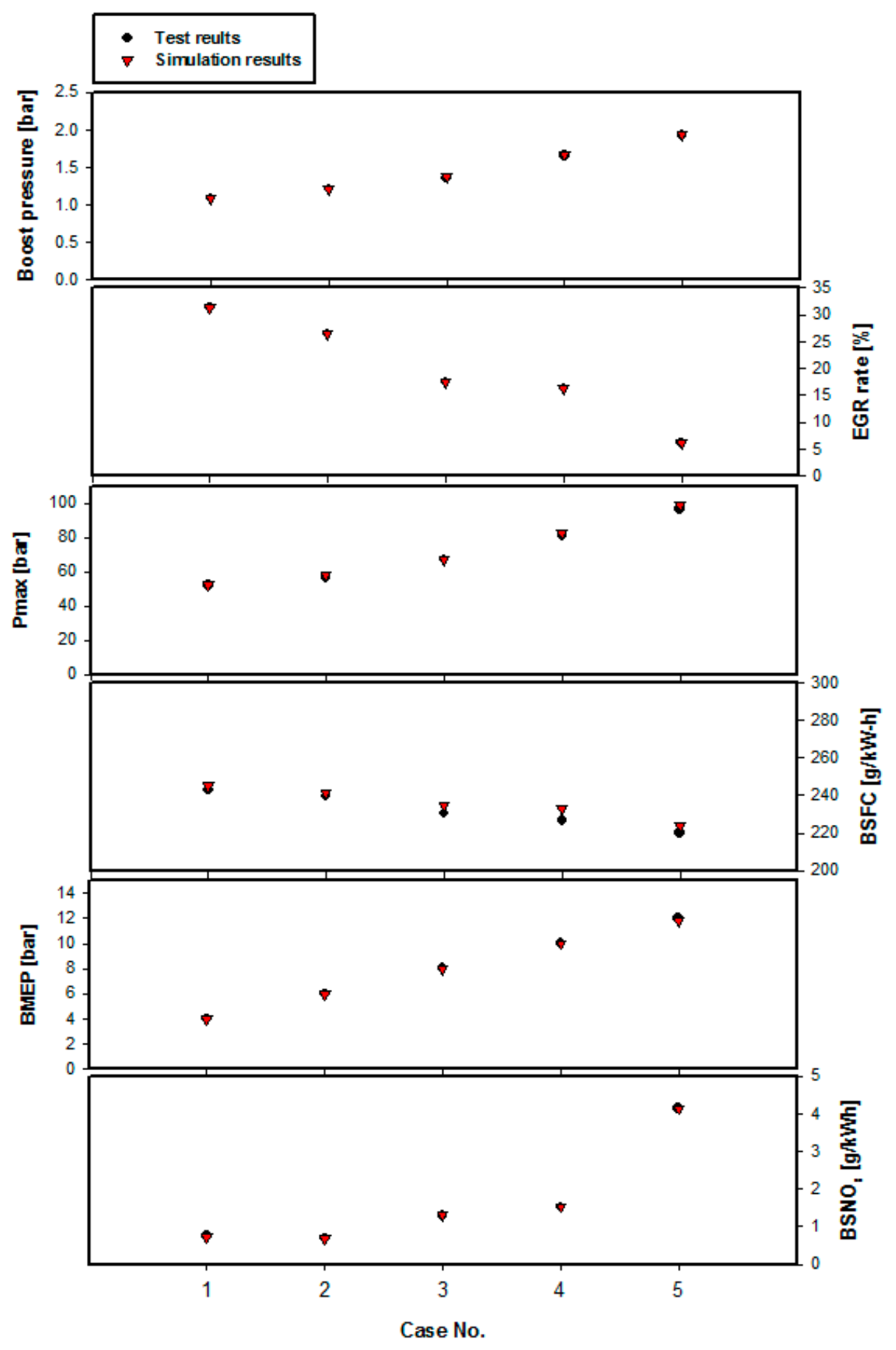

Figure 7. Comparison between experimental and numerical results: boost pressure, EGR rate, maximum cylinder pressure, brake-specific fuel consumption (BSFC), BMEP, and brake-specific $\mathrm{NO}_{\mathrm{x}}\left(\mathrm{BSNO}_{\mathrm{x}}\right)$.

Before applying eS and the dual-loop EGR system, a constant BEMP controller was attached to the engine model and heavy EGR was applied (Figure 8). Heavy EGR was applied to induce as much EGR as the engine could take. The heavy EGR rates that were applied and the base EGR rates are shown in Table 5. As shown in Figure 8, when the EGR fraction increased compared with the base engine operating conditions in Table 3, due to a dilution effect, Pmax and maximum temperature were reduced, causing $\mathrm{NO}_{x}$ emissions to also be reduced. As the EGR rate was increased-but with total boost pressure and rpm conditions being constrained-the total air flow rate decreased, resulting in a decreasing A/F ratio. As a result, the BSFC results deteriorated, by a maximum of $4 \%$, but $\mathrm{NO}_{\mathrm{x}}$ emissions were reduced by a maximum of $84 \%$. These results represent the basic effects of LTC on a 
diesel engine and are similar to those obtained in previous investigations $[6-8,15,27]$. However, for a passenger car diesel engine, fuel efficiency is as important as emissions for operations and sales. Thus, there is a need to apply and optimize eS and a dual-loop EGR system to reduce emissions and increase fuel efficiency.
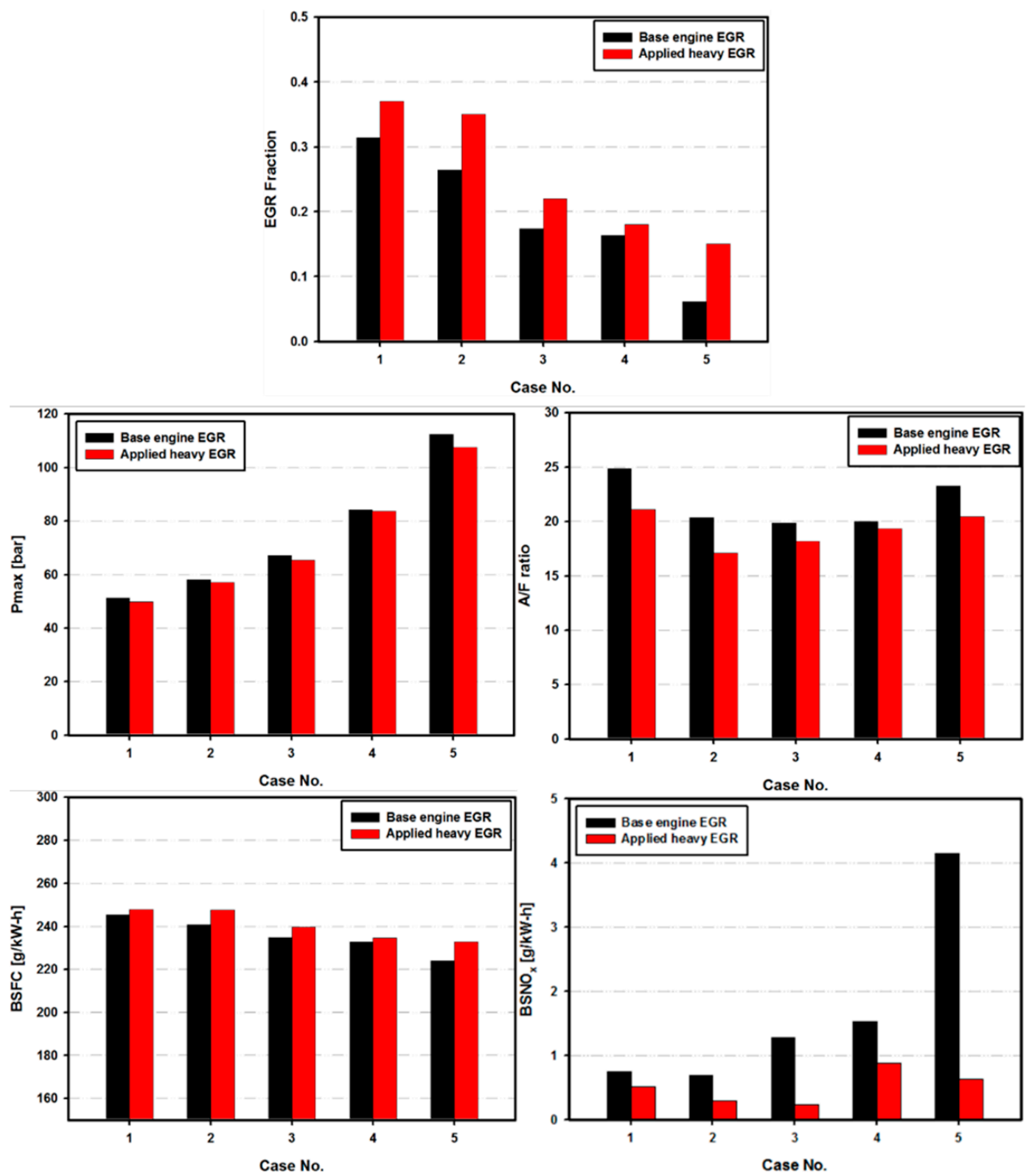

Figure 8. Comparison of EGR rate, maximum in-cylinder pressure (Pmax), air fuel (A/F) ratio, BSFC, and $\mathrm{BSNO}_{\mathrm{x}}$ between the base engine and heavy EGR-applied engine in each case.

Table 5. Heavy EGR application.

\begin{tabular}{ccc}
\hline Case No. & Base EGR (\%) & Heavy EGR (\%) \\
\hline 1 & 31.4 & 37 \\
2 & 26.4 & 35 \\
3 & 17.4 & 22 \\
4 & 16.3 & 18 \\
5 & 6.1 & 15 \\
\hline
\end{tabular}




\subsection{Effects of the LP Fraction and eS rpm and Power on Fuel Efficiency}

Before applying the dual-loop EGR and eS, the effects of LP-fraction, eS power, and rpm were investigated by a full-factorial DoE method. When investigating the effects of eS rpm, it was found to increase from 40,000 to 160,000, in 5000 intervals, with power held at $0.5 \mathrm{~kW}$. When investigating the effects of eS power, it was found to increase from 0.1 to $1.5 \mathrm{~kW}$, in 0.1 intervals, with rpm held at $70,000 \mathrm{rpm}$. In each case, the LP fraction was divided into five cases, ranging from 0 to $1(0,0.25,0.5$, 0.75 , and 1.0). In case 1 , with the LP fraction being equal to 1, the LP-EGR pressure was lower than that of the intake air and the EGR induction rate was not satisfied. Thus, comparison and optimization of an LP fraction of 1 in case 1 would be meaningless.

The effects of LP-fraction, eS rpm, and power on fuel efficiency in case 2 are shown on the left side of Figure 9. In this study, fuel efficiency was determined by BSFC. With increasing eS, rpm, and eS power, the engine intake pressure was increased. Thus, the thermal efficiency of the engine was increased by the enhanced intake pressure. Moreover, as the LP fraction in each case increased, the fuel efficiency was enhanced. This was influenced by the compressor and eS efficiency increasing because the air flow rate was increased by the LP-EGR induction rate being increased in all cases. Results in other cases were similar to those of case 2 .

Case No. 2

1750 RPM BMEP 6 bar
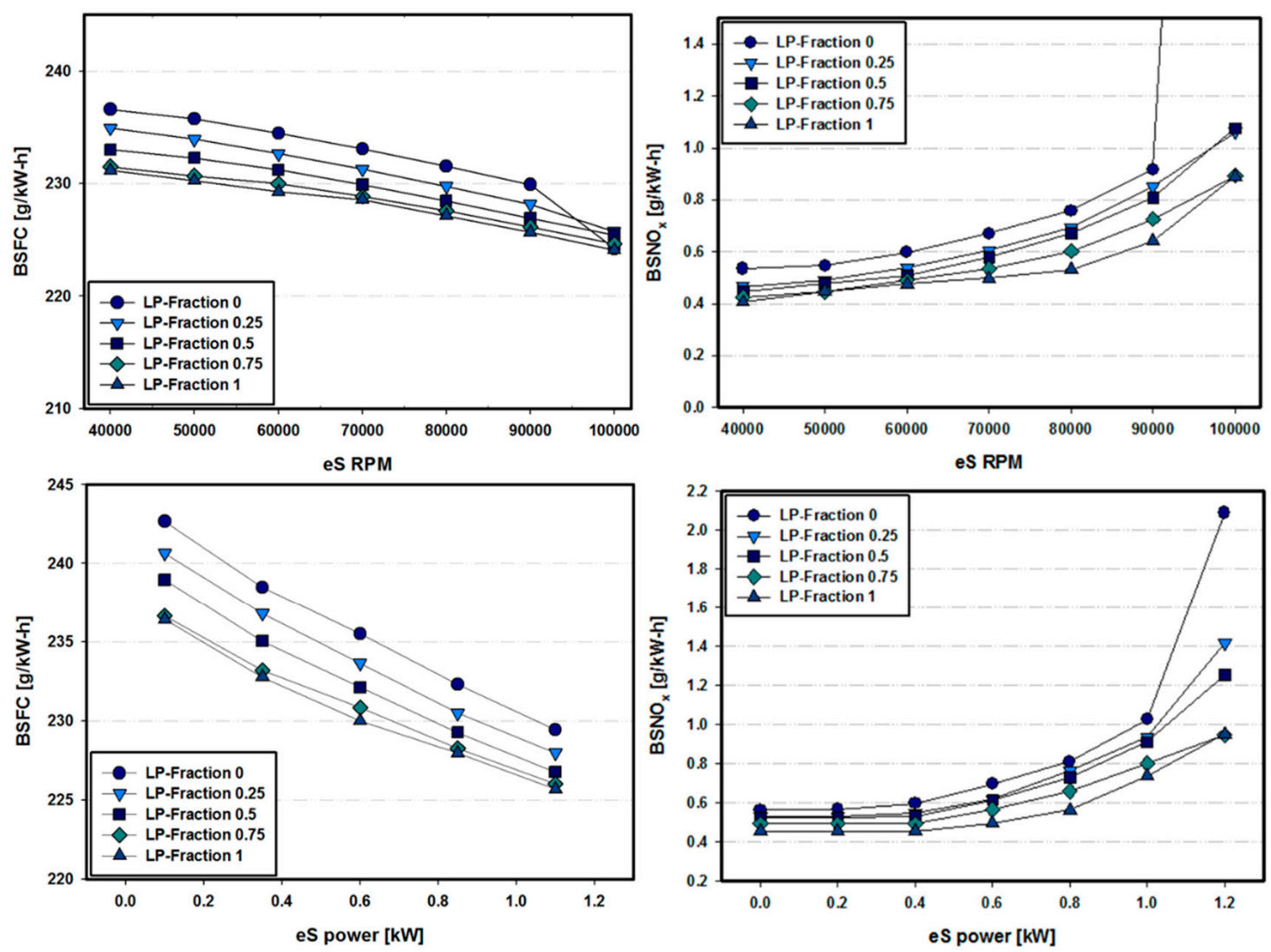

Figure 9. BSFC and $\mathrm{BSNO}_{\mathrm{x}}$ differences due to eS rpm and power increases in case 2.

In Figure 9, the BSFC was decreased by $4.5 \%$, at 10,000 versus at $9000 \mathrm{rpm}$. This was because the EGR induction rate was not fully satisfied due to the intake pressure increasing. This will be discussed in the next chapter. These results were similar to previous reports [15,27-33]. 


\subsection{Effects of LP Fraction, eS rpm, and Power on $\mathrm{NO}_{x}$ Emissions}

In this study, the $\mathrm{NO}_{x}$ emission was determined by $\mathrm{BSNO}_{x}$. The effects of LP fraction, eS rpm, and power on $\mathrm{NO}_{x}$ emissions are shown on the right side of Figure 9. As the eS rpm and power increased, the fuel efficiency improved as a result of better thermal efficiency. However, as the thermal efficiency improved, the in-cylinder pressure and temperature increased. As a result, thermal $\mathrm{NO}_{\mathrm{x}}$ increased due to the higher eS power and rpm. As the LP fraction in each case increased, the $\mathrm{NO}_{\mathrm{x}}$ emission was reduced due to the cooled EGR (because the intake air increased). The cooled EGR has better dilution characteristics than the HP-EGR. In case 2 (Figure 9) the $\mathrm{BSNO}_{\mathrm{x}}$ increased rapidly when eS rpm was 10,000 rpm in LP fraction 0 cases, because as the eS power and rpm increased, the intake air pressure became higher than the EGR pressure of the HP-EGR, thereby decreasing the EGR induction rate. Thus, the $\mathrm{NO}_{\mathrm{x}}$ emissions increased due to a lack of EGR. Results for the other cases were similar to those of case 2. Moreover, these results were similar to those of previous research [15,27-33].

From the previous chapter and this one, it can be seen that, as the eS rpm or power increased, the fuel efficiency improved, but $\mathrm{NO}_{\mathrm{x}}$ emissions also increased due to the higher in-cylinder pressure and temperature. Thus, to improve fuel efficiency and $\mathrm{NO}_{\mathrm{x}}$ emissions simultaneously under heavy EGR, dual-loop EGR, and eS conditions, a DoE and multi-objective Pareto optimization method should be applied.

\subsection{DoE and Multi-Objective Pareto Optimization}

The results showed that BSFC decreased as brake thermal efficiency increased. Moreover, as efficiency increased, $\mathrm{NO}_{x}$ emissions increased simultaneously. These characteristics were influenced by the heavy EGR, eS power, rpm, and LP fraction. Thus, to improve thermal efficiency and $\mathrm{NO}_{\mathrm{x}}$ emissions simultaneously, the DoE and multi-objective Pareto optimization procedures were used because the trade-off between related parameters can be optimized (here, between BSFC and BSNO ${ }_{x}$ ). The detailed DoE parameters and ranges in each case are shown in Table 4. For each constant BMEP condition, the LP fraction ranged from $0-1$, except for case 1 . The eS rpm range was controlled according to the results given in Sections 3.2 and 3.3. In total, 400 cases were investigated in all LP fractions. After the sampling, response surface plots were prepared using the sampling simulation data and the RBFN fitting method. The RBFN fitting method has several advantages and it is used widely in DoE methods [34]. In Figure 10, the response surface plots given by the RBFN are shown. In case 1 , for each LP fraction, BSFC and $\mathrm{BSNO}_{x}$ are plotted as functions of the variables eS rpm and eS power. BSFC and $\mathrm{BSNO}_{x}$ functions were determined by these response surface plots in all cases and all LP fractions.

After RBFN fitting, multi-objective Pareto optimization was performed to minimize both BSFC and $\mathrm{BSNO}_{x}$; the feasible points to minimize both results are optimal Pareto fronts. These optimal Pareto fronts and the base engine data are shown in Figure 11. By applying and optimizing heavy EGR and eS with dual-loop EGR, engine efficiency and emission characteristics were improved simultaneously. In case 1 (Figure 11), four LP fractions were investigated with a lack of EGR induction rate in LP fraction 1. In each feasible Pareto-optimal front, the conditions of eS power and rpm were fixed. Thus, by controlling eS power and rpm through these feasible fronts, the engine could be controlled to meet the target BSFC or $\mathrm{BSNO}_{x}$, while minimizing the other trade-off results. In each case, BSFC and $\mathrm{BSNO}_{x}$ decreased with increasing LP fraction. Through the Pareto front lines, as the A/F ratio of the engine increased, the $\mathrm{BSNO}_{\mathrm{x}}$ increased with decreased BSFC. In cases 1-4, eS power was dominant in controlling the $\mathrm{A} / \mathrm{F}$ ratio, but in case 5 , the $\mathrm{A} / \mathrm{F}$ ratio was controlled predominantly by eS rpm. 
Case No. 5

2250 RPM BMEP 12 bar
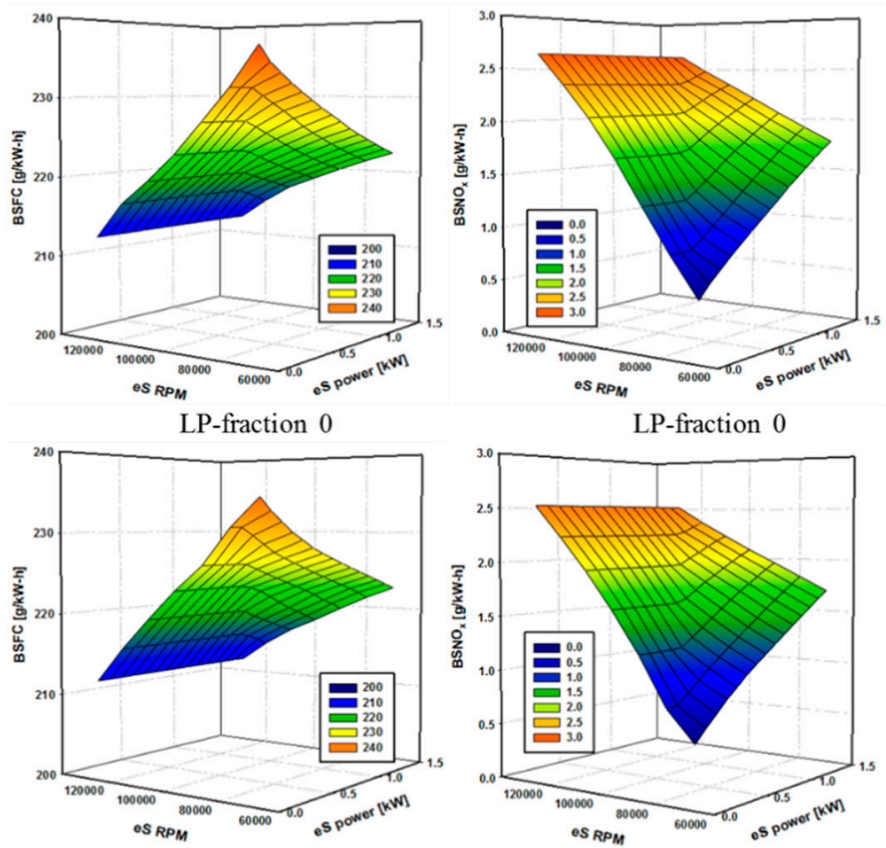

LP-fraction 0.25

LP-fraction 0.25
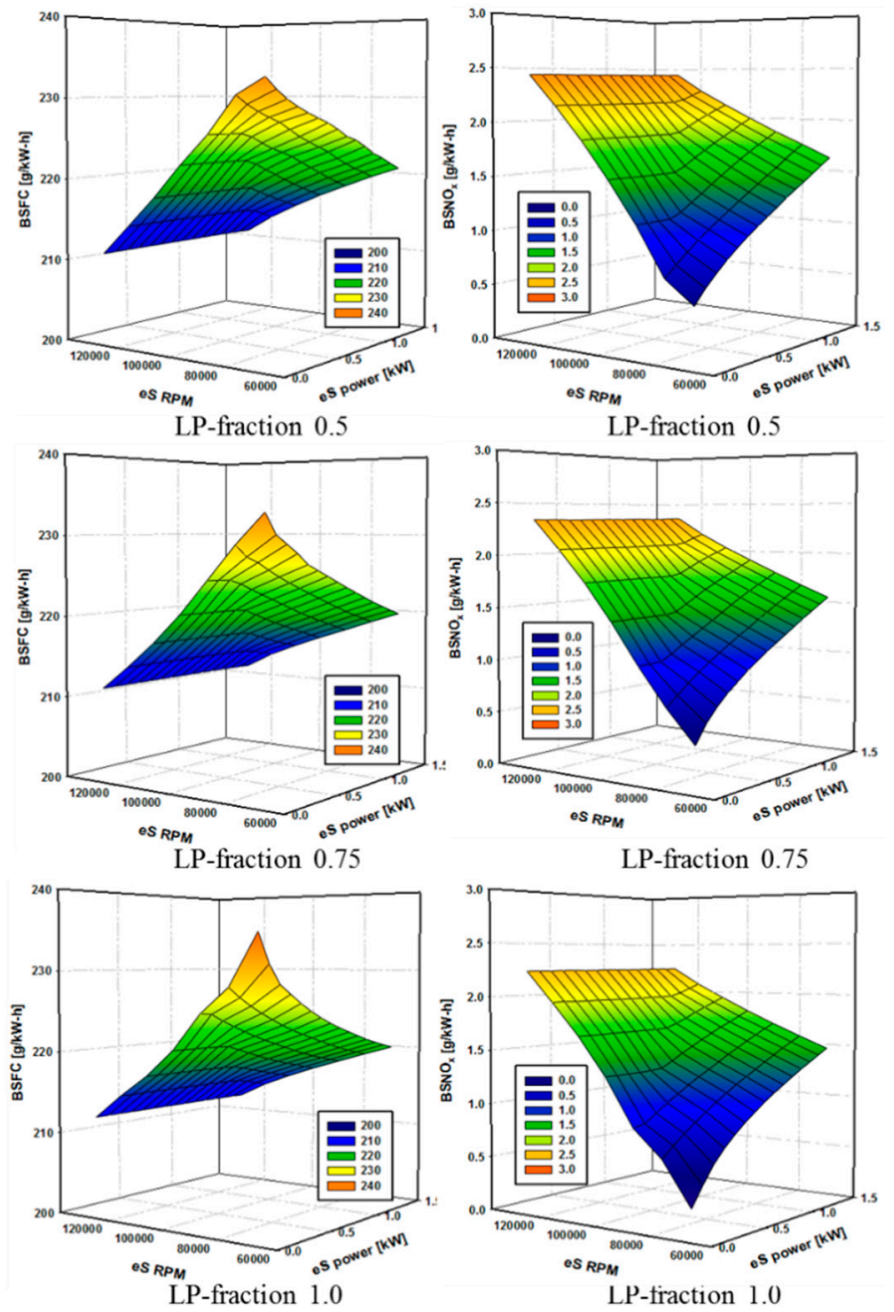

Figure 10. Response surface plots for BSFC and $\mathrm{BSNO}_{\mathrm{x}}$ in case 5 for each LP fraction. 
Case No. 1

1500 RPM BMEP 4bar

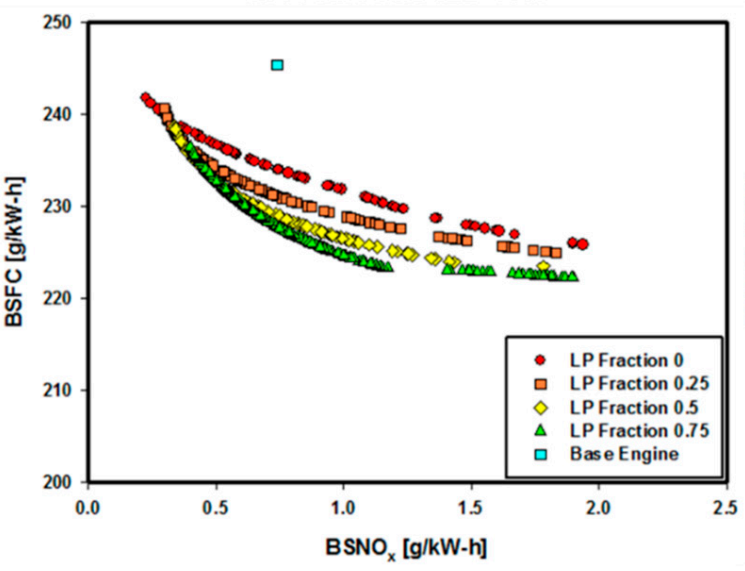

Case No. 3

1750 RPM BMEP 8bar

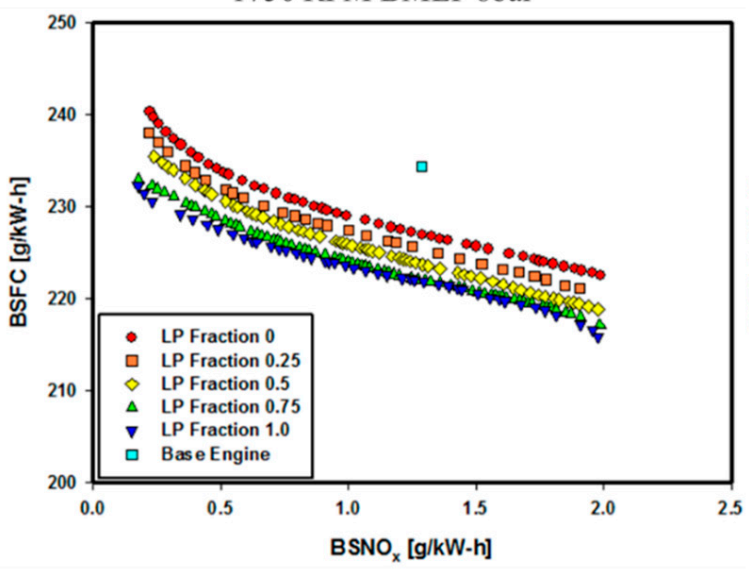

Case No. 5

2250 RPM BMEP 12 bar

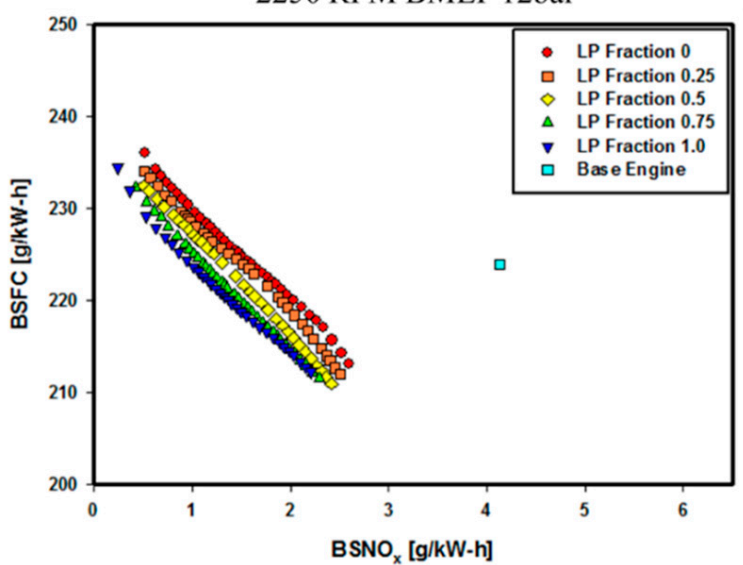

Case No. 2

1750 RPM BMEP 6 bar

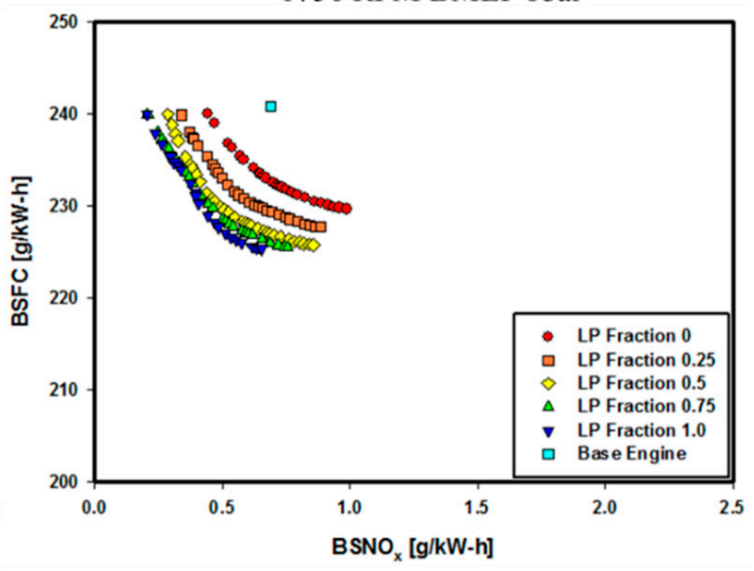

Case No. 4

2000 RPM BMEP 10 bar

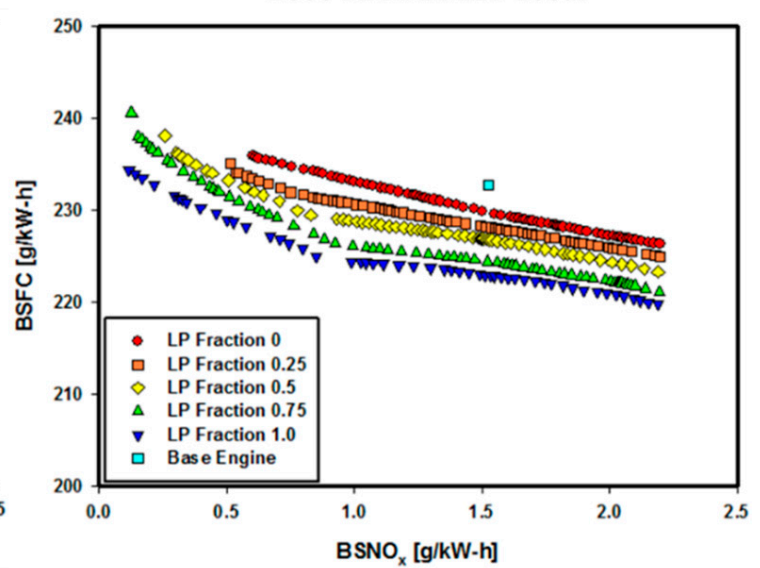

Figure 11. Pareto-optimal front with various low-pressure (LP) fractions for all cases.

Figures 12-16 show the A/F variation through Pareto front lines and dominant A/F controlling factors: eS power versus rpm. The controlling parameters are discussed in detail in the next section. 
Case No. 1

1500 RPM BMEP 4bar LP-fraction 0.25

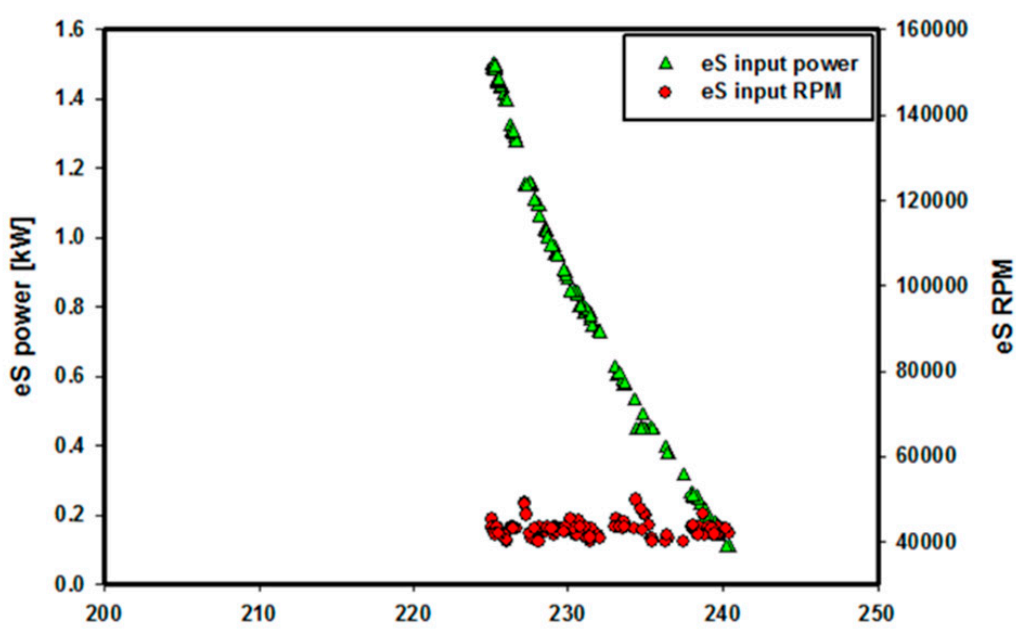

BSFC [g/kW-h]
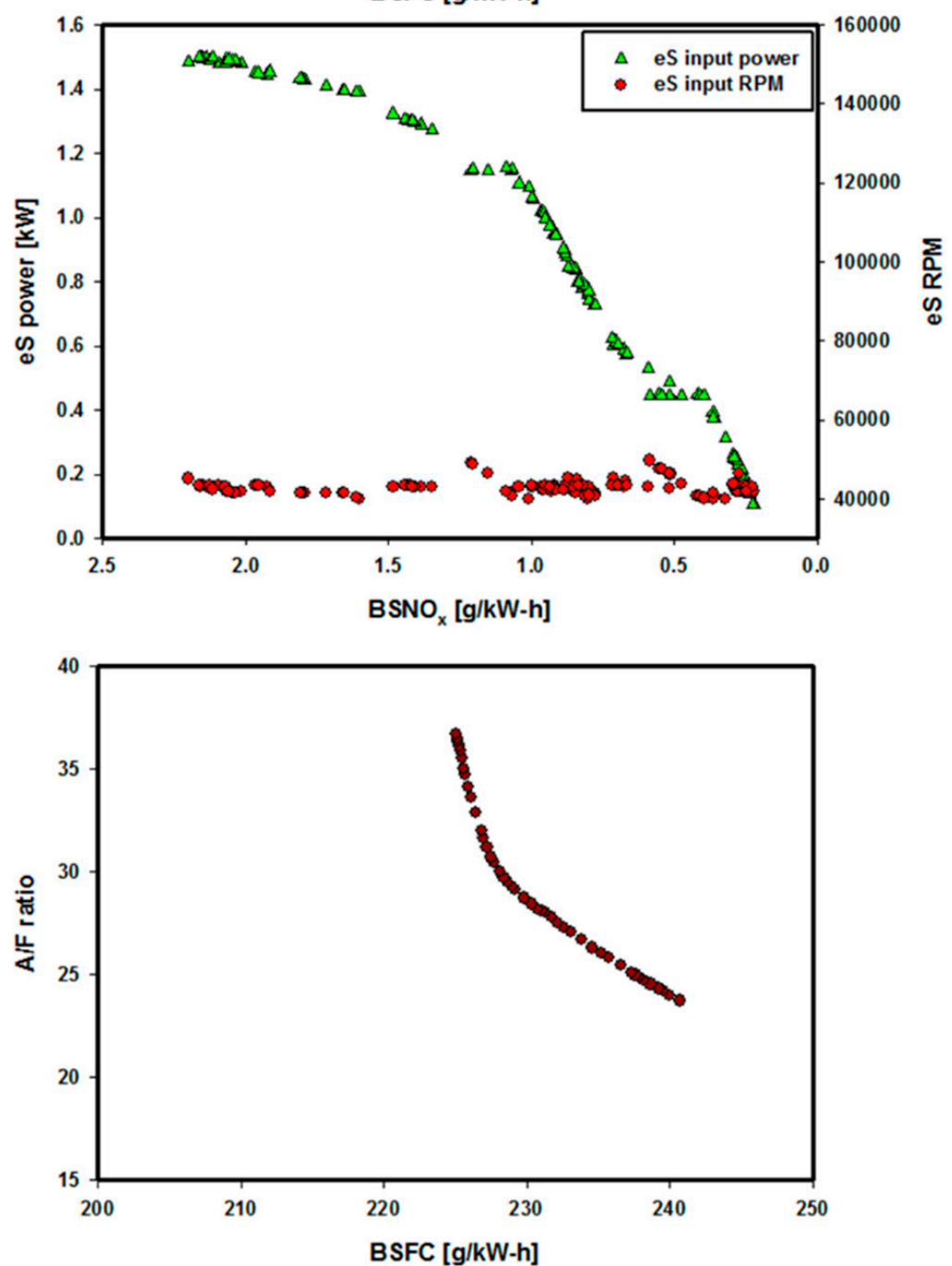

Figure 12. $\mathrm{BSFC}, \mathrm{BSNO}_{\mathrm{x}}$, and $\mathrm{A} / \mathrm{F}$ ratio differences on the Pareto front line of case 1 (LP fraction $\left.=0.25\right)$. 
Case No. 2
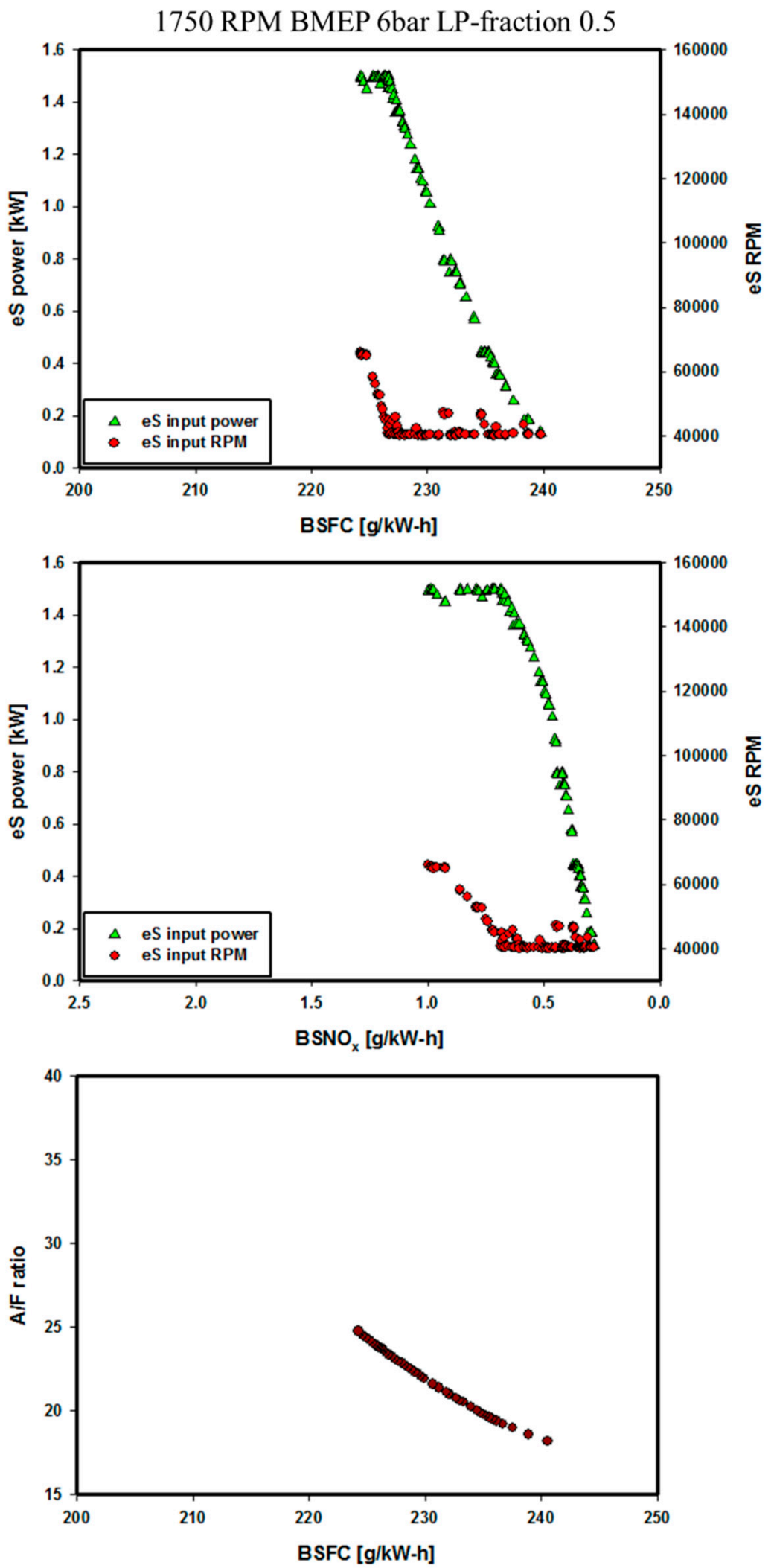

Figure 13. $\mathrm{BSFC}, \mathrm{BSNO}_{\mathrm{x}}$, and $\mathrm{A} / \mathrm{F}$ ratio difference on the Pareto front line of case 2 (LP fraction $\left.=0.5\right)$. 
Case No. 3

1750 RPM BMEP 8bar LP-fraction 0.5
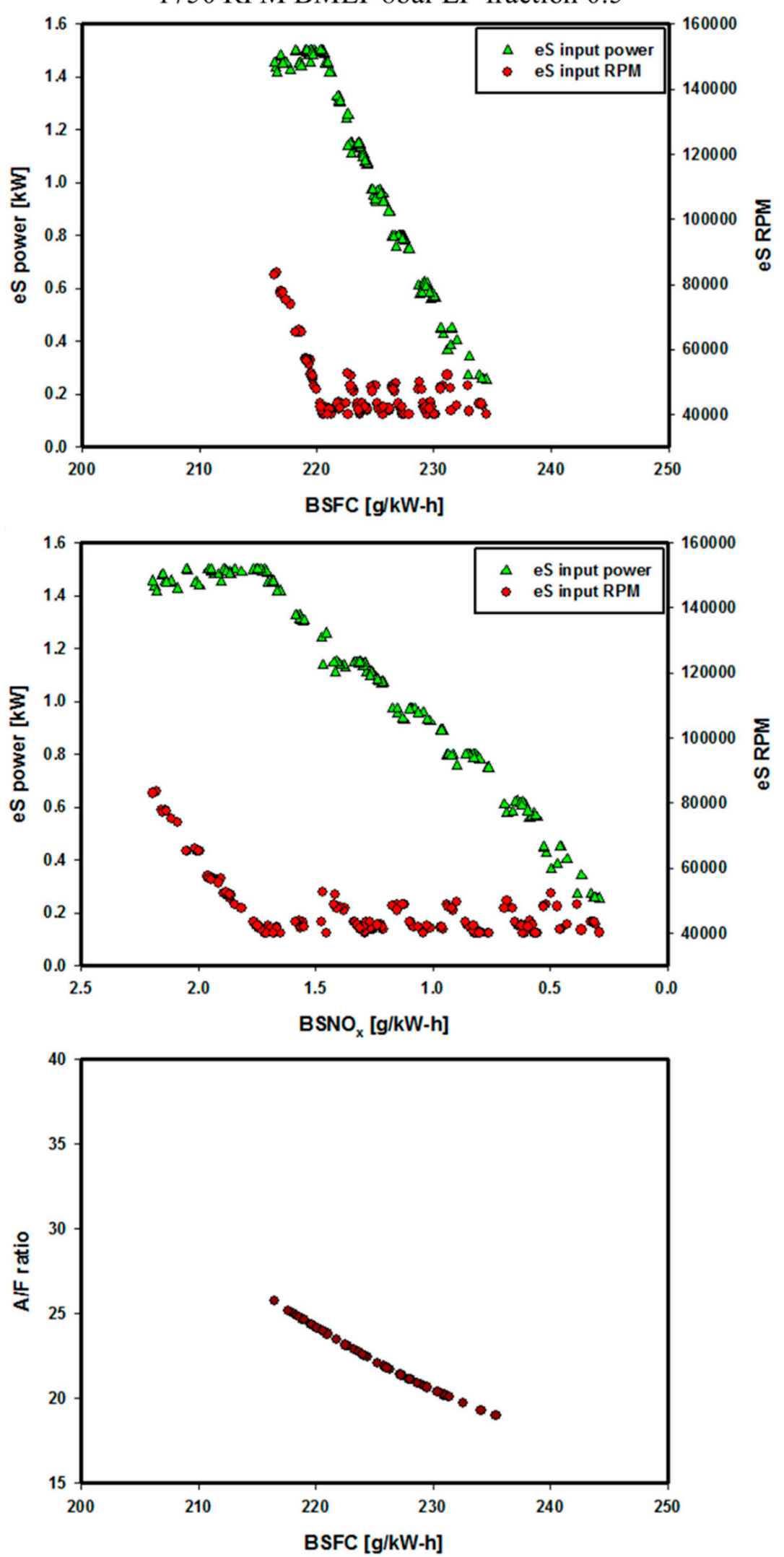

Figure 14. $\mathrm{BSFC}, \mathrm{BSNO}_{\mathrm{x}}$, and $\mathrm{A} / \mathrm{F}$ ratio differences on the Pareto front line of case 3 (LP fraction $=0.5$ ). 
Case No. 4
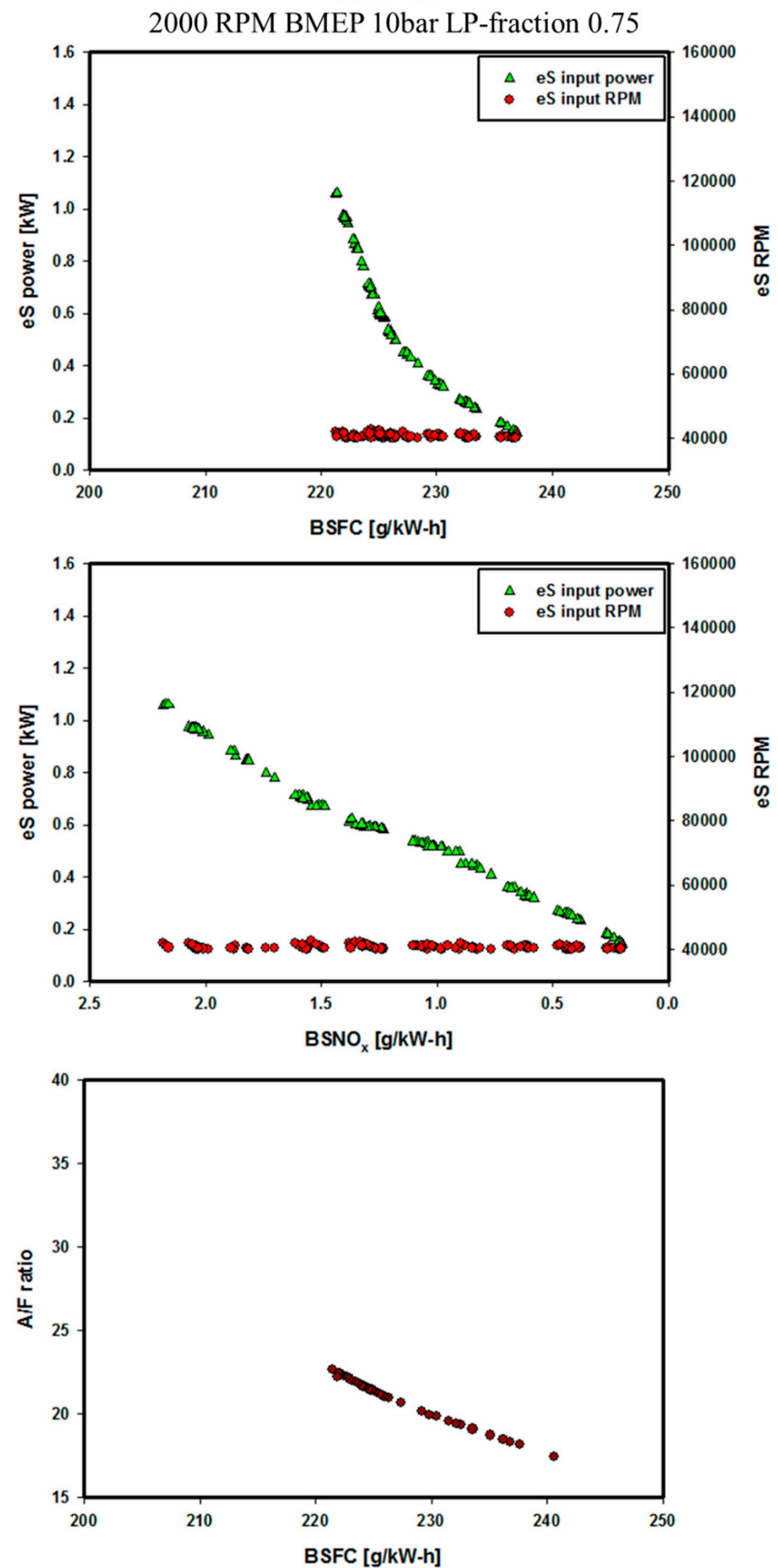

Figure 15. BSFC, $\mathrm{BSNO}_{x}$, and A/F ratio differences on the Pareto front line of case 4 (LP fraction $\left.=0.75\right)$. 
Case No. 5

2250 RPM BMEP 12bar LP-fraction 1
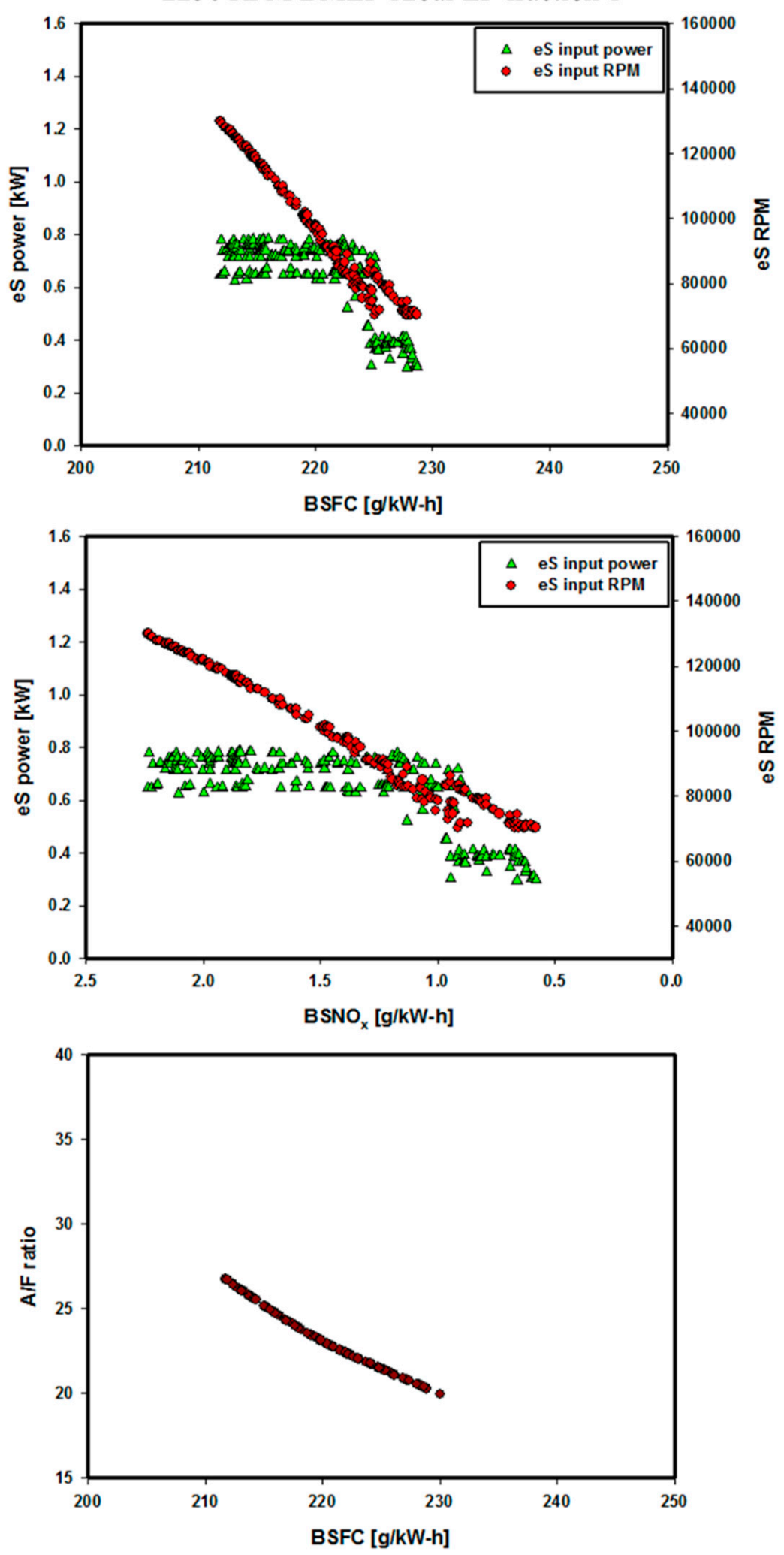

Figure 16. $\mathrm{BSFC}, \mathrm{BSNO}_{\mathrm{x}}$, and $\mathrm{A} / \mathrm{F}$ ratio differences on the Pareto front line of case 5 (LP fraction $=1.0$ ). 


\subsection{Design Parameter Recommendations}

In Figures 12-16, the eS power, eS rpm, and A/F ratio variations are plotted through Pareto fronts on typical LP fractions in each case (LP fractions: case $1,0.25$; cases 2 and 3, 0.5 ; case $4,0.75$; case 5, 1.0). In each case, BSFC decreased and $\mathrm{BSNO}_{\mathrm{x}}$ increased as the $\mathrm{A} / \mathrm{F}$ ratio increased through Pareto-optimal lines. In cases $1-4$, the $\mathrm{A} / \mathrm{F}$ ratio was controlled predominantly by eS power. Case 1 was a low-load operation condition where the air flow rate was low. Thus, as eS power increased, the A/F ratio increased dramatically. In cases 2 and 3, the A/F ratio was controlled primarily by eS power. However, as it reached the maximum power of $\mathrm{eS}=1.5 \mathrm{~kW}$, the $\mathrm{A} / \mathrm{F}$ ratio was controlled by increasing eS rpm. This means that more air can be introduced into the engine by increasing eS rpm when the maximum power is already applied. In case 4 , the A/F ratio was controlled only by eS power. This was because the base boost pressure in case 4 was 1.68 bar, which is high enough, and the EGR rate difference between the base and heavy EGR condition was quite low $(\sim 10.42 \%)$ versus the other conditions. In case 5 , the $\mathrm{A} / \mathrm{F}$ ratio was controlled predominantly by eS $\mathrm{rpm}$. This will be discussed in the next chapter.

\subsection{LP Fraction Effects on eS Power and rpm}

In Section 3.3, the effects of LP fraction on fuel efficiency and $\mathrm{NO}_{\mathrm{x}}$ emissions were investigated. The fuel efficiency increased and $\mathrm{NO}_{\mathrm{x}}$ emissions decreased. In Figures 17-19, the effects of LP fraction on eS power and rpm are shown. In cases 3 and 4, eS power was the major variable controlling the A/F ratio. As the LP fraction increased, the eS power decreased at the same BSFC level. This is because, at the same pressure ratio, the air flow rate increases when the LP fraction increases, making the eS operate with higher efficiency. In case 5, Figure 19 shows that eS power was the major controller of the $\mathrm{A} / \mathrm{F}$ ratio in the LP fraction 0 case. However, as the LP fraction increased, eS rpm became the dominant controller of the A/F ratio. In the cases wherein the LP fraction $=0.5$ and 1.0, as the LP fraction increased, eS power and rpm decreased under the same BSFC conditions. This was for the same reason as in cases 3 and 4, i.e., the eS operated in a higher efficiency area as the LP fraction increased.

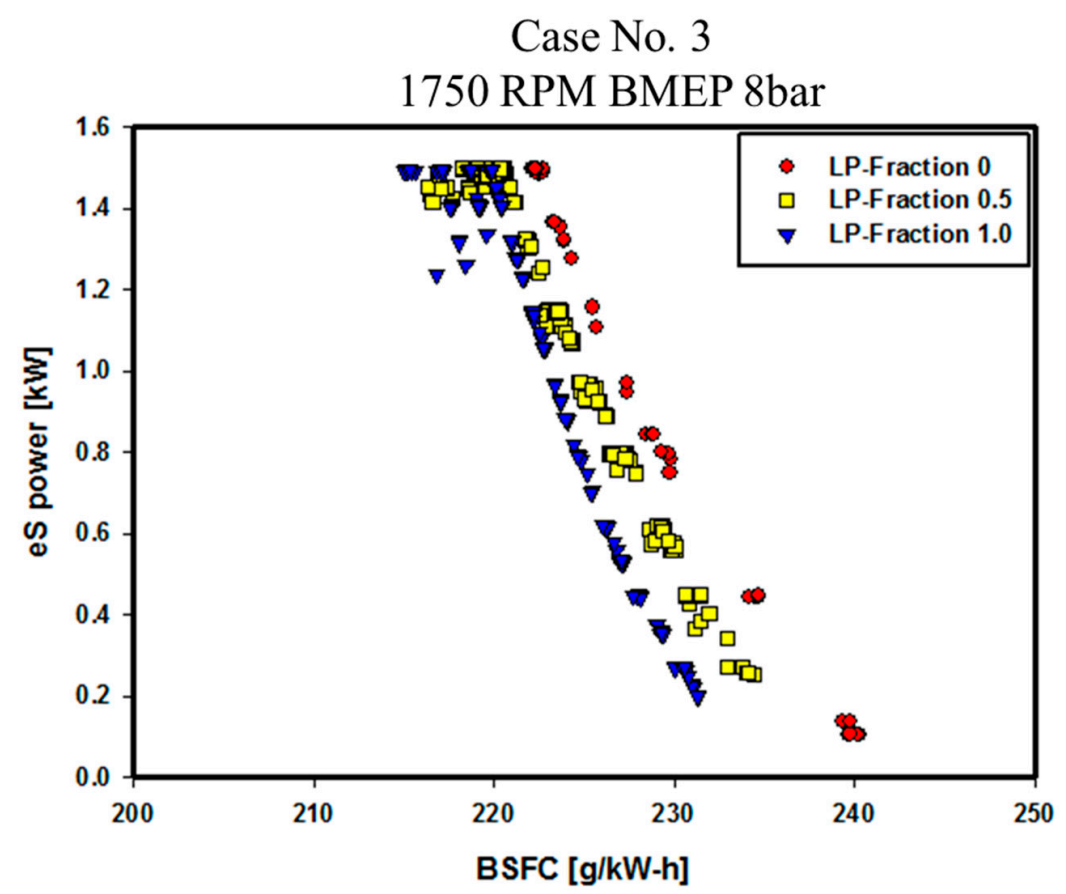

Figure 17. eS power difference for various LP fractions on the Pareto front line of case 3. 
Case No. 4

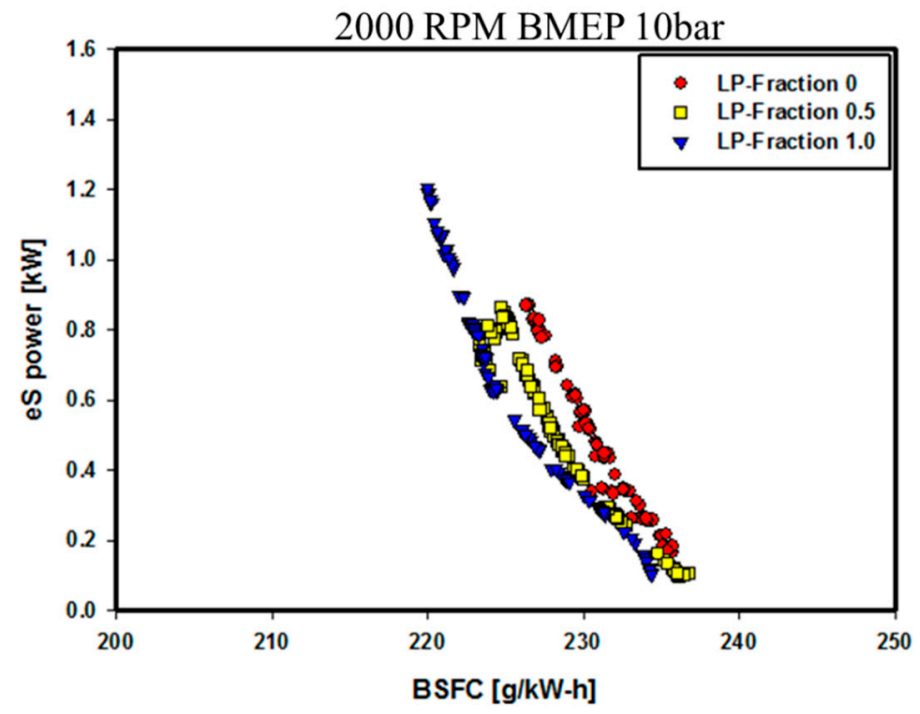

Figure 18. eS power difference for various LP fractions on the Pareto front line of case 4.

Case No. 5

2250 RPM BMEP 12bar
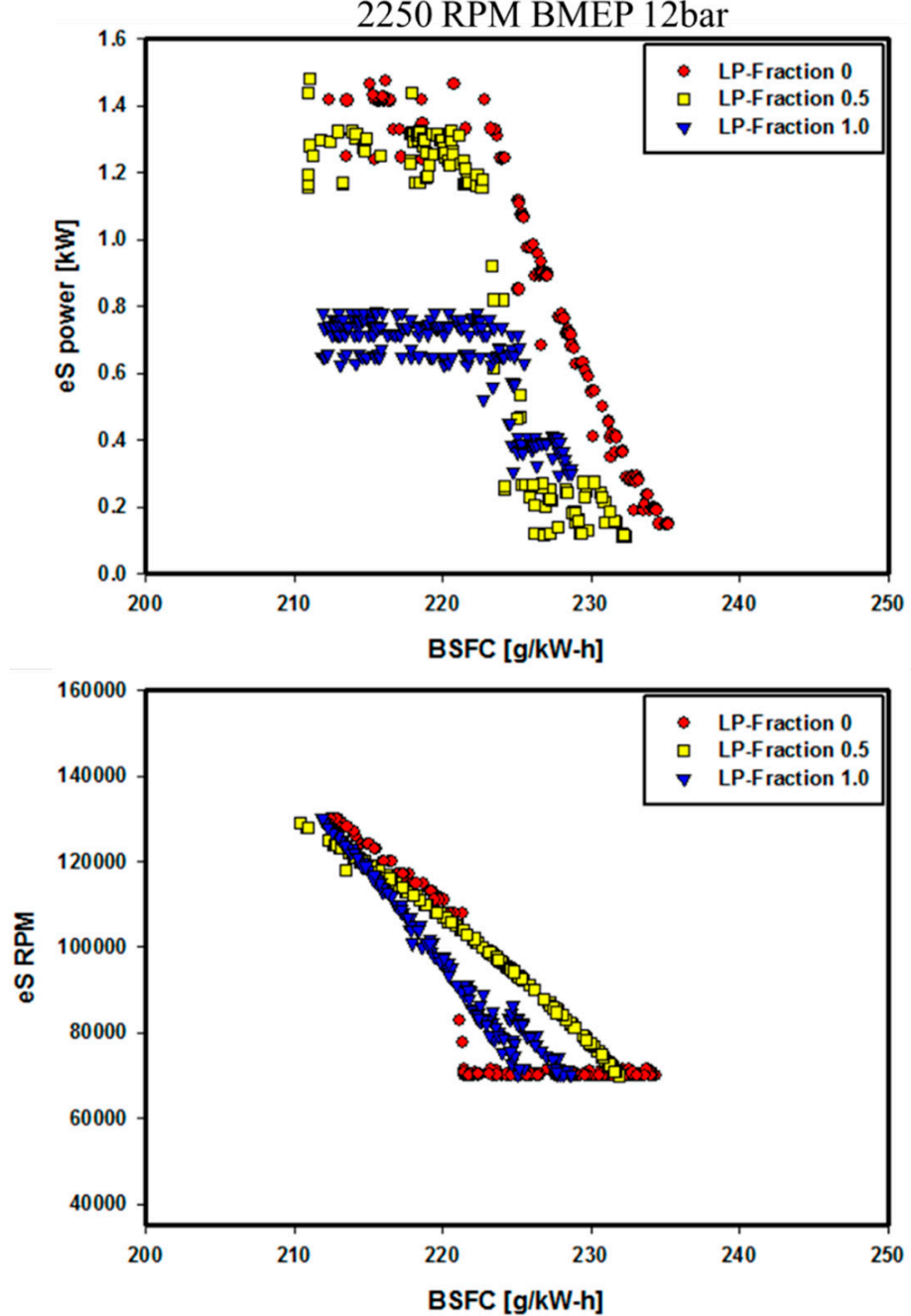

Figure 19. eS power and rpm differences for various LP fractions on the Pareto front line of case 5. 


\subsection{Optimization Results}

In Figures 20 and 21, the base engine, heavy EGR conditions, and optimization results are compared. The selected LP fractions are case 1 with an LP fraction of 0.25 , cases 2 and 3 with LP fractions of 0.5 , case 4 with an LP fraction of 0.75 , and case 5 with an LP fraction of 1.0. The top panel of Figure 20 shows the intake pressure of the base engine and the eS pressure ratio and the optimized intake pressures. In case 4 , the eS pressure ratio was lower than that of the other cases, so that its $\mathrm{A} / \mathrm{F}$ ratio was controlled by eS power alone. In the bottom panel of Figure 20, the A/F ratios are compared. By applying heavy EGR, the A/F ratio decreased. However, by applying and optimizing eS, the A/F ratio increased, so that the thermal efficiency of the engine also increased. However, in the case of an intake pressure increase, Pmax would also be expected to increase. In the top panel of Figure 21, Pmax for the optimized engine is shown. The maximum Pmax was 112.53 bar, which was lower than the engine's maximum pressure limit (165 bar). Thus, it was rational to apply the maximum Pmax. As shown in the middle panel of Figure 21, the BSFC under all conditions decreased when applying and optimizing eS and dual-loop EGR. BSFC decreased by a maximum of $5.86 \%$ in case 1 . However, for the whole engine system, the eS power of $0.54 \mathrm{~kW}$ needs to be considered. Finally in the bottom panel of Figure 21, by applying heavy EGR and dual-loop EGR, BSNO $_{x}$ decreased with better thermal efficiency. $\mathrm{BSNO}_{\mathrm{x}}$ decreased by a maximum of $63.73 \%$ in case 5 . In case 1 , BSFC decreased by $5.86 \%$ but $\mathrm{BSNO}_{\mathrm{x}}$ decreased by $32.87 \%$ simultaneously.
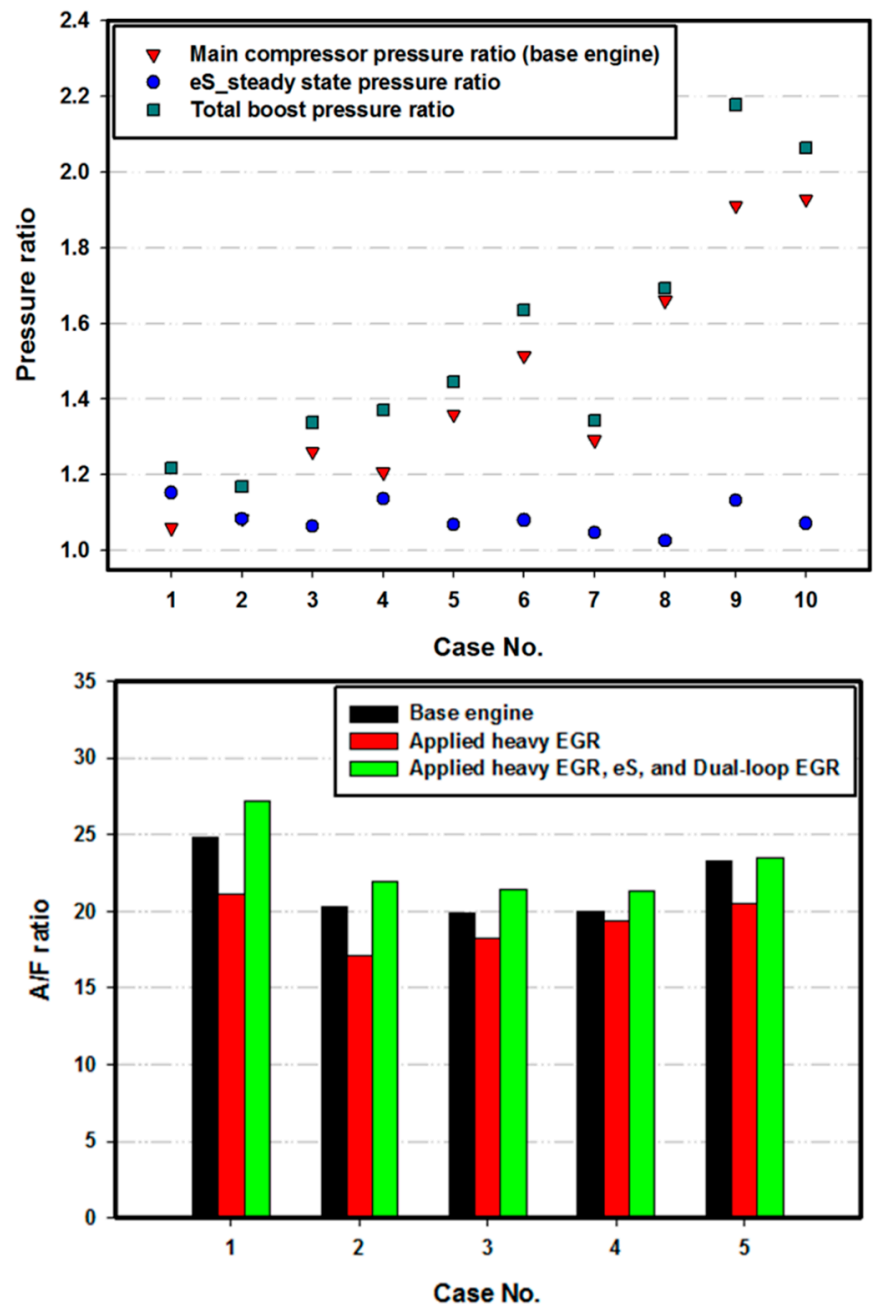

Figure 20. Pressure ratio difference from base to optimized engine and comparison of base engine, heavy EGR, and optimized engine with respect to air fuel ratio. 

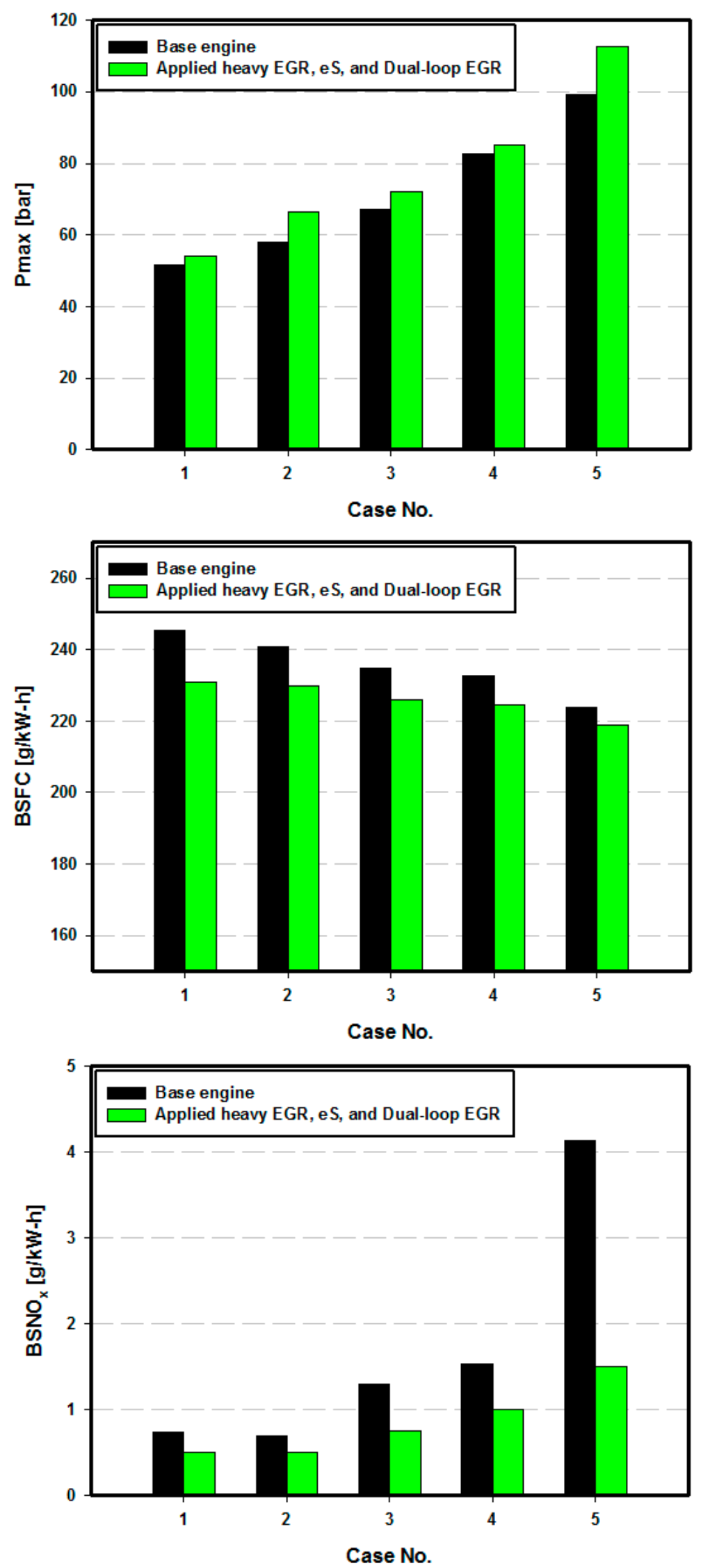

Figure 21. Comparison of base engine and optimized engine with respect to Pmax, $\mathrm{BSFC}$, and $\mathrm{BSNO}_{\mathrm{x}}$. 


\section{Conclusions}

The fuel efficiency and $\mathrm{NO}_{x}$ emission characteristics of a 1.4 passenger car diesel engine with an $\mathrm{eS}$ and dual-loop EGR system were investigated using a 1D engine cycle simulation. Both BSFC and $\mathrm{BSNO}_{\mathrm{x}}$ were improved simultaneously using a multi-objective Pareto optimization process.

The results of the study can be summarized as follows:

- The engine model was validated with experimental data in five WLTP reference states, using the DI-pulse combustion model. A constant BMEP controller, an eS, and a dual-loop EGR system were added to investigate their effects on the diesel engine.

- Heavy EGR was applied in each case. By applying heavy EGR, $\mathrm{NO}_{x}$ emissions were decreased by a maximum of $84 \%$, whereas BSFC deteriorated by a maximum of $4 \%$.

- The effects of eS power, eS rpm, and LP fraction were investigated under constant BMEP conditions. As eS power and rpm increased, the BSFC of the engine decreased. This was because the thermal efficiency also increased due to an increase in intake pressure. However, the increase in $\mathrm{BSNO}_{\mathrm{x}}$ was due to an increase in thermal $\mathrm{NO}_{\mathrm{x}}$ emissions. Moreover, as the LP-fraction increased, BSFC and $\mathrm{BSNO}_{x}$ both decreased due to the increased efficiency of the turbocharger and the cooled EGR.

- Using DoE and RBFN methods, response surface plots of BSFC and BSNO $\mathrm{B}_{x}$ were obtained according to eS power and rpm under all LP fraction conditions. A multi-objective Pareto optimization was conducted using response surface plots and optimal Pareto fronts were obtained.

- By tracking the A/F ratio through the Pareto front lines, it was seen that, although as the A/F ratio increased the fuel efficiency of the engine increased, $\mathrm{NO}_{x}$ emissions also increased simultaneously. The A/F ratio was controlled primarily by eS power. As the LP fraction increased, the power needed to obtain the same BSFC decreased. This was because eS efficiency increased in response to an increase in the air flow rate. However, in case 5, as the LP fraction increased, eS rpm became the major controller of the A/F ratio and little extra power was needed to achieve the same BSFC.

- $\quad$ By applying and optimizing heavy EGR, eS, and dual-loop EGR, $\mathrm{NO}_{x}$ emissions were decreased by $63.73 \%$ in case 5 . Moreover, the efficiency was improved by a maximum of $5.86 \%$ in case 1 , in which the $\mathrm{NO}_{x}$ emissions were decreased by $32.87 \%$.

Author Contributions: Conceptualization, methodoloty, valiation, formal analysis, investigation and writing-original draft preparatin, H.Y.; supervision, B.Y.P.; funding acquisition, H.C.; writing-review and editing, and supervision, J.P.

Funding: This work was supported by "Human Resources Program in Energy Technology" of the Korea Institute of Energy Technology Evaluation and Planning (KETEP), granted financial resource from the Ministry of Trade, Industry \& Energy, Republic of Korea. (No. 20194030202410) and also supported by the Korea Institute of Energy Technology Evaluation and Planning(KETEP) and the Ministry of Trade, Industry \& Energy(MOTIE) of the Republic of Korea (No. 20184010201650).

Conflicts of Interest: The authors declare no conflict of interest.

$\begin{array}{ll}\text { Abbreviations } \\ \text { CI } & \text { Compression ignition } \\ \mathrm{NO}_{x} & \text { Nitrogen oxides } \\ \text { PM } & \text { Particulate matters } \\ \text { WLTP } & \text { Worldwide harmonized light-duty vehicles test procedures } \\ \text { EGR } & \text { Exhaust gas recirculation } \\ \text { DPF } & \text { Diesel particulate filter } \\ \text { LNT } & \text { Lean NO } \text { trap } \\ \text { SCR } & \text { Selective catalytic reduction } \\ \text { eS } & \text { Electric supercharger } \\ \text { LTC } & \text { Low-temperature combustion } \\ \text { HP-EGR } & \text { High-pressure EGR } \\ \text { LP-EGR } & \text { Low-pressure EGR }\end{array}$




$\begin{array}{ll}\text { HECC } & \text { High-efficiency clean combustion } \\ \text { BSNO }_{x} & \text { Brake-specific } \mathrm{NO}_{x} \\ \text { ESI } & \text { EGR split index } \\ \text { NEDC } & \text { New European Driving Cycle } \\ \text { BSFC } & \text { Brake-specific fuel consumption } \\ \text { DoE } & \text { Design of experiment } \\ \text { BMEP } & \text { Brake mean effective pressure } \\ \text { A/F ratio } & \text { Air fuel ratio } \\ \text { TDC } & \text { Top dead center } \\ \text { PID } & \text { Proportional integral derivative } \\ \text { DI-pulse } & \text { Diesel multi-pulse } \\ \text { IVC } & \text { Intake valve closing } \\ \text { LHS } & \text { Latin hypercube sampling } \\ \text { RBFN } & \text { Radial basis function network } \\ \text { rpm } & \text { revolution per minute } \\ \text { LSM } & \text { Least-squares method } \\ \text { ANN } & \text { Artificial neural network }\end{array}$

\section{References}

1. Heywood, J.B. Internal Combustion Engine Fundamentals; Mcgraw-Hill: New York, NY, USA, 1988.

2. Aoyagi, Y.; Kunishima, E.; Asaumi, Y.; Aihara, Y.; Odaka, M.; Goto, Y. Diesel Combustion and Emission Study by Using of High Boost and High Injection Pressure in Single Cylinder Engine: The effects of boost pressure and timing retardation on thermal efficiency and exhaust emissions (Diesel Engines, Performance and Emissions, Thermal Efficiency). In Proceedings of the International Symposium on Diagnostics and Modeling of Combustion in Internal Combustion Engines, Yokohama, Japan, 02 August 2004; pp. 119-126.

3. Aoyagi, Y.; Osada, H.; Misawa, M.; Hirosawa, T.; Odaka, M.; Goto, Y. Diesel emission reduction using high boost and high EGR rate in a single cylinder engine. Rev. Automot. Eng. 2005, 26, 391.

4. Wakisaka, Y.; Hotta, Y.; Inayoshi, M.; Nakakita, K.; Sakata, I.; Takano, T. Emissions reduction potential of extremely high boost and high EGR rate for an HSDI diesel engine and the reduction mechanisms of exhaust emissions. SAE Int. J. Fuels Lubr. 2008, 1, 611-623. [CrossRef]

5. Maiboom, A.; Tauzia, X.; Hétet, J.F. Experimental study of various effects of exhaust gas recirculation (EGR) on combustion and emissions of an automotive direct injection diesel engine. Energy 2008, 33, 22-34. [CrossRef]

6. NOx reduction in High Boost, Wide Range and High EGR Rate in a Heavy Duty Diesel Engine. Available online: https://www.researchgate.net/publication/280294531_Effective_NOx_Reduction_in_High_Boost_ Wide_Range_and_High_EGR_Rate_in_a_Heavy_Duty_Diesel_Engine (accessed on 15 October 2019).

7. Effective BSFC and NOx Reduction on Super Clean Diesel of Heavy Duty Diesel Engine by High Boosting and High EGR Rate. Available online: https://www.researchgate.net/publication/278304516_Effective_BSFC_ and_NOx_Reduction_on_Super_Clean_Diesel_of_Heavy_Duty_Diesel_Engine_by_High_Boosting_and_ High_EGR_Rate (accessed on 15 October 2019).

8. Emission Reduction Potential by Means of High Boost and Injection Pressure at Low-and Mid-Load for a Common Rail Diesel Engine under High EGR Rates. Available online: https://www.researchgate. net/publication/287183801_Emission_Reduction_Potential_by_Means_of_High_Boost_and_Injection_ Pressure_at_Low-_and_Mid-Load_for_a_Common_Rail_Diesel_Engine_under_High_EGR_Rates (accessed on 15 October 2019).

9. Lee, Y.; Huh, K.Y. Analysis of different modes of low temperature combustion by ultra-high EGR and modulated kinetics in a heavy duty diesel engine. Appl. Therm. Eng. 2014, 70, 776-787. [CrossRef]

10. Abu-Hamdeh, N.H. Effect of cooling the recirculated exhaust gases on diesel engine emissions. Energy Convers. Manag. 2003, 44, 3113-3124. [CrossRef]

11. Zheng, M.; Reader, G.T.; Hawley, J.G. Diesel engine exhaust gas recirculation-a review on advanced and novel concepts. Energy Convers. Manag. 2004, 45, 883-900. [CrossRef]

12. Millo, F.; Giacominetto, P.F.; Bernardi, M.G. Analysis of different exhaust gas recirculation architectures for passenger car diesel engines. Appl. Energy 2012, 98, 79-91. [CrossRef] 
13. Cho, K.; Han, M.; Wagner, R.M.; Sluder, C.S. Mixed-source EGR for enabling high efficiency clean combustion modes in a light-duty diesel engine. SAE Int. J. Engines 2008, 1, 457-465. [CrossRef]

14. Park, J.; Song, S.; Lee, K.S. Numerical investigation of a dual-loop EGR split strategy using a split index and multi-objective Pareto optimization. Appl. Energy 2015, 142, 21-32. [CrossRef]

15. Comparison among Different 2-Stage Supercharging Systems for Hsdi Diesel Engines. Available online: https://www.researchgate.net/publication/293815169_Comparison_among_different_2-Stage_ Supercharging_systems_for_HSDI_Diesel_engines (accessed on 15 October 2019).

16. Tang, Q.; Fu, J.; Liu, J.; Boulet, B.; Tan, L.; Zhao, Z. Comparison and analysis of the effects of various improved turbocharging approaches on gasoline engine transient performances. Appl. Therm. Eng. 2016, 93, 797-812. [CrossRef]

17. Developing a Performance Specification for an Electric Supercharger to Satisfy a Range of Downsized Gasoline Engine Applications. Available online: https://www.researchgate.net/publication/301242971_Developing_a_ Performance_Specification_for_an_Electric_Supercharger_to_Satisfy_a_Range_of_Downsized_Gasoline_ Engine_Applications (accessed on 15 October 2019).

18. Salehi, R.; Martz, J.; Stefanopoulou, A.; Hansen, T.; Haughton, A. Comparison of High-and Low-Pressure Electric Supercharging of a HDD Engine: Steady State and Dynamic Air-Path Considerations; SAE Technical Paper No. 2016-01-1035; SAE: Troy, MI, USA, 2016.

19. GT-Suite Version 7.3; Manual; Gamma Technologies Inc.: Westmont, IL, USA, 2012.

20. Park, J.; Lee, K.S.; Kim, M.S.; Jung, D. Numerical analysis of a dual-fueled CI (compression ignition) engine using Latin hypercube sampling and multi-objective Pareto optimization. Energy 2014, 70, 278-287. [CrossRef]

21. Jung, C.; Park, J.; Song, S. Performance and NOx emissions of a biogas-fueled turbocharged internal combustion engine. Energy 2015, 86, 186-195. [CrossRef]

22. Multi-Objective Optimization of Diesel Engine Emissions and Fuel Economy Using Genetic Algorithms and Phenomenological Model. Available online: https://www.researchgate.net/publication/265870790_MultiObjective_Optimization_of_Diesel_Engine_Emissions_and_Fuel_Economy_using_Genetic_Algorithms_ and_Phenomenological_Model (accessed on 15 October 2019).

23. Reduction of Heavy Duty Diesel Engine Emission and Fuel Economy with Multi-Objective Genetic Algorithm and Phenomenological Model. Available online: https://www.researchgate.net/publication/ 267954576_Reduction_of_Heavy_Duty_Diesel_Engine_Emission_and_Fuel_Economy_with_Multi-

Objective_Genetic_Algorithm_and_Phenomenological_Model (accessed on 15 October 2019).

24. Atashkari, K.; Nariman-Zadeh, N.; Gölcü, M.; Khalkhali, A.; Jamali, A. Modelling and multi-objective optimization of a variable valve-timing spark-ignition engine using polynomial neural networks and evolutionary algorithms. Energy Convers. Manag. 2007, 48, 1029-1041. [CrossRef]

25. Wei, L.; Yuying, Y. Multi-objective optimization of sheet metal forming process using Pareto-based genetic algorithm. J. Mater. Process. Technol. 2008, 208, 499-506. [CrossRef]

26. Deb, M.; Banerjee, R.; Majumder, A.; Sastry, G. Multi objective optimization of performance parameters of a single cylinder diesel engine with hydrogen as a dual fuel using pareto-based genetic algorithm. Int. J. Hydroen Energy 2014, 39, 8063-8077. [CrossRef]

27. Maiboom, A.; Tauzia, X.; Shah, S.R.; Hétet, J.F. Experimental Study of an LP EGR System on an Automotive Diesel Engine, compared to HP EGR with respect to PM and NOx Emissions and Specific Fuel Consumption. SAE Int. J. Engines 2009, 2, 597-610. [CrossRef]

28. Appliance of High EGR Rates with a Short and Long Route EGR System on a Heavy Duty Diesel Engine. Available online: https://www.researchgate.net/publication/228487814_Appliance_of_High_ EGR_Rates_With_a_Short_and_Long_Route_EGR_System_on_a_Heavy_Duty_Diesel_Engine (accessed on 15 October 2019).

29. Development of a 2-Stage Supercharging System for a HSDI Diesel Engine. Available online: https://researchgate.net/publication/293816611_Development_of_a_2-Stage_Supercharging_System_for_ a_HSDI_Diesel_Engine (accessed on 15 October 2019).

30. Keidel, S.; Wetzel, P.; Biller, B.; Bevan, K.; Birckett, A. Diesel engine fuel economy improvement enabled by supercharging and downspeeding. SAE Int. J. Commer. Veh. 2012, 5, 483-493. [CrossRef] 
31. Newman, P.; Luard, N.; Jarvis, S.; Richardson, S.; Smith, T.; Jackson, R. Electrical supercharging for future diesel powertrain applications. In Proceedings of the 11th International Conference on Turbochargers and Turbocharging, London, UK, 13-14 May 2014; pp. 207-216.

32. Effects of Dual Loop EGR on Performance and Emissions of a Diesel Engine. Available online: https: //www.sae.org/publications/technical-papers/content/2015-01-0873/ (accessed on 15 October 2019).

33. Benjey, R.P.; Biller, B.; Tsourapas, V. Cost effective hybrid boosting solution with application to light duty vocational vehicles. Int. J. Powertrains 2015, 4, 302-314. [CrossRef]

34. Qi, X.; Yuan, Z.; Han, X. Diagnosis of misalignment faults by tacholess order tracking analysis and RBF networks. Neurocomputing 2015, 169, 439-448. [CrossRef]

(C) 2019 by the authors. Licensee MDPI, Basel, Switzerland. This article is an open access article distributed under the terms and conditions of the Creative Commons Attribution (CC BY) license (http://creativecommons.org/licenses/by/4.0/). 